\title{
Interactions of Engineered Nanoparticles with Organs Protected by Internal Biological Barriers
}

\author{
Antonio Pietroiusti, * Luisa Campagnolo, and Bengt Fadeel
}

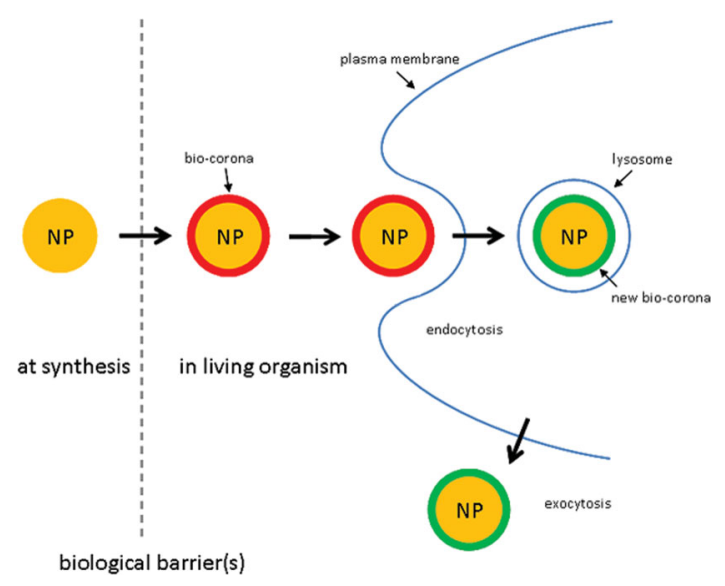

From the Contents

1. Introduction. ..................

2. How do ENPs Cross Internal Barriers? . . . . 2

3. The Blood-Brain Barrier and the BloodTestis Barrier ................ 5

4. The Placental Barrier 10

5. Do ENPs Impact on Injured Internal Barriers?

6. Summary and Outlook .
$\boldsymbol{E}_{\text {ngineered nanomaterials may exert adverse effects }}$ on human health which, in turn, may be linked to their propensity to cross biological barriers in the body. Here, available evidence is discussed, based on in vivo studies for interactions of commercially relevant nanoparticles with critical internal barriers. The internal barriers in focus in this review are the blood-brain barrier, protecting the brain, the blood-testis barrier, protecting the male germ line, and the placenta, protecting the developing fetus. The route of exposure (pulmonary, gastro-intestinal, intravenous, intraperitoneal, dermal), and, hence, the portal of entry of nanoparticles into the body, is of critical importance. Different physicochemical properties, not only size, may determine the ability of nanoparticles to breach biological barriers; the situation is further compounded by the formation of a so-called corona of biomolecules on the surfaces of nanoparticles, the composition of which may vary depending on the route of exposure and the translocation of nanoparticles from one biological compartment to another. The relevance of nanoparticle interactions with internal biological barriers for their impact on the organs protected by these barriers is also discussed. 


\section{Introduction}

An almost endless number of potential injuring agents like viruses, bacteria, dust, and physical agents surround humans. However, their access into the body is strongly limited by a sophisticated protective system represented by mechanical, chemical and functional barriers. At the borders with the external environment there are three anatomical primary barriers represented by the epithelia of the skin, the gastrointestinal tract and the respiratory system. In the unfortunate event that these barriers are overcome, further biological barriers protecting strategic sites are present inside the body. These internal or secondary barriers are the blood-brain barrier $(\mathrm{BBB})$, protecting the brain, the blood-testis barrier (BTB), protecting the male reproductive apparatus, and the placenta, protecting the developing embryo. Thus, much like castles in historical times, these critical organs are protected not only by a moat to protect the perimeter of the castle, but also by an inner wall around the castle itself.

The evolutionary choice of a dual protection of these organs and organ systems is clear: the brain is the coordinating centre of the physiological activities of the organism, and the integrity of the testes and the embryo is crucial for the reproduction of the species. No matter how well protected, no castle or fortress is impregnable, and this holds true also for organs protected by internal barriers. In fact, these barriers may be damaged or destroyed in some cases, ${ }^{[1]}$ but most frequently they may be circumvented. The small size of nanoparticles (NPs), less than $100 \mathrm{~nm}$, makes them similar to physiological molecules, and might allow them to utilize the same mechanisms of entry across internal barriers. On this basis, extensive research regarding the possible use of appropriately designed NPs for the diagnosis and treatment of diseases in organs protected by the internal barriers has been developed during the last years. ${ }^{[2]}$ On the other hand, the same peculiar features of NPs, produced for industrial and/or commercial purposes (engineered NPs [ENPs]), pose growing concern about their possible unintentional access to these highly protected organs, once they come in contact with workers or consumers. ${ }^{[3,4]}$

Current evidence of the ability of worker-relevant and consumer-relevant ENPs to cross internal barriers and/or to cause toxicological effects, is the focus of this review. In our analysis, we will refer mainly to available in vivo studies. In fact, the anatomy and physiology of internal barriers are very complex: although sophisticated in vitro models have been developed, ${ }^{[5,6]}$ they can hardly mimic the in vivo process of ENP translocation through these barriers. In addition, none of the in vitro experiments conducted to date takes into account the surface modification of ENPs inside the human body (i.e. their coating with body proteins and lipids, with the formation of the so-called corona). ${ }^{[7]}$ This dynamic process strongly influences the cellular and paracellular crossing of ENPs: according to size and surface properties, different types of protein corona and different temporal patterns of protein corona formation are detectable in ENPs having the same chemical composition (Figure 1). ${ }^{[8,9]}$ The portal of entry is decisive. For instance, pulmonary phospholipid coating may change the pattern of adsorbed proteins, in turn influencing significantly the interaction and subsequent effects of ENPs on biological systems. ${ }^{[10-13]}$ The matter of the physico-chemical changes of ENPs travelling along the gastrointestinal (GI) tract and the formation of different coronas during this 'fantastic voyage' through the body is currently largely unexplored. In this review, we aim to address the following issues: Do ENPs reach and cross secondary barriers, and to what extent? Does the exposure route influence the crossing of internal barriers by ENPs? Are there differences in the crossing of different internal barriers? What are the mechanisms of ENP-induced damage of the internal organs? May different physiological and pathological conditions influence the crossing and damaging processes? We will not, however, discuss interactions of ENPs with primary anatomical barriers, i.e. lung, skin, and gastro-intestinal tract as this topic has been subject to several excellent reviews elsewhere. ${ }^{[14-16]}$

\section{How do ENPs Cross Internal Barriers?}

To understand how ENPs cross biological barriers one must first address the physico-chemical properties of the materials; in addition, the acquisition of a 'corona' of biomolecules on the surface of ENPs may also determine whether ENPs are able to cross from one compartment to another and whether they are taken up effectively by cells or not. ${ }^{[17]}$ ENPs, once internalized by cells, may also exit through a process of exocytosis. ${ }^{[18,19]}$ Therefore, ENPs in the extracellular environment may be covered with different biomolecules at any given time depending on whether or not they have undergone endocytosis/exocytosis. This situation is illustrated in Figure 1. However, it should be noted that the bio-corona may also play a role in other, undesirable effects of ENPs in living systems such as complement activation and blood clotting, and may not necessarily play a role only in cellular uptake. ${ }^{[20]}$ For a recent discussion of how various ENM properties such as hydrophobicity and hydrophilicity, chemical composition, surface functionalization and charge, dispersal state, as well as the adsorption of proteins on the surface determine cellular uptake, see Zhu et al. ${ }^{[21]}$ Regarding the crossing of biological barriers, most studies to date are related to the inhalation route of exposure. For instance, using radiolabelled nanoparticles of either carbon or iridium, Kreyling et al. ${ }^{[22]}$ were able to derive quantitative biodistribution data in rats on the translocation of NPs from lungs to circulation and their accumulation in secondary taget organs. The authors found that material composition as well

Prof. A. Pietroiusti, Prof. L. Campagnolo Department of Biomedicine and Prevention University of Rome Tor Vergata

via Montpellier 1, 00133, Rome, Italy

E-mail: pietroiu@uniroma2.it

Prof. B. Fadeel

Division of Molecular Toxicology

Institute of Environmental Medicine

Nobels väg 13, 171 77, Karolinska Institutet, Stockholm, Sweden

DOI: 10.1002/smll.201201463 
as the size of the chain-like aggregates of the ENPs determined their translocation. In a study of the oral exposure route, radiolabelled gold nanoparticles of different sizes were administered by intra-oesophageal instillation in rats. ${ }^{[23]}$ The highest accumulation in secondary organs was found for the smallest $(1.4 \mathrm{~nm})$ particles and negatively charged particles accumulated in sercondary organs more than the positively charged NPs. Of note, the $18 \mathrm{~nm}$ particles showed a higher accumulation in brain and heart compared to other sized particles. Choi et al. ${ }^{[24]}$ performed a systematic assesssment of the role of hydrodynamic size and surface charge for biodistribution and elimination of NIR fluorescent NPs in a rat model after lung instillation. NPs with a hydrodynamic size of less than $34 \mathrm{~nm}$ translocated rapidly from the lung to mediastinal lymph nodes; importantly, below the size threshold of $34 \mathrm{~nm}$, the surface charge was also critical for translocation to occur. Moreover, the bio-corona played a role insofar as the adsorption of proteins affected the hydrodynamic size of the NPs. Particles with a hydrodynamic size of less than $6 \mathrm{~nm}$ were trafficked from the lungs via the lymph nodes into the bloodstream leading ultimately to renal clearance of the NPs. Thus, the material-intrinsic properties and the bio-corona in concert may determine the propensity for ENPs to cross a biological barrier eg. the alveolar-capillary or the gastrointestinal barrier.

The main mechanisms for crossing of internal barriers are passive and active transport, and endocytosis, respectively. Although organized as highly protective systems, internal barriers must allow the transport of nutrients to the brain, to the fetus and to the testes. There are two main mechanisms through which these physiological substances may cross internal barriers: passive diffusion (simple or facilitated) and active diffusion. In passive diffusion, crossing occurs through a concentration gradient across the barrier, and passage of solutes occurs between cells (i.e., paracellular) or across cells (i.e., transcellular). In the case of passive facilitated diffusion, the passage of solutes is always regulated by a concentration gradient without any energy expenditure; however, the equilibrium is reached faster than in simple passive diffusion because transport is facilitated by influx transporters. Of note, a concentration gradient is a condition necessary but not sufficient to allow the passage through the barriers by these mechanisms; some other conditions, such as size, hydrophobicity, polarity and protein binding, among others, must be present. Similarly to passive facilitated transport, active transport of solutes is mediated by influx transporters; however it occurs against a concentration gradient, and involves energy expenditure. The transport systems described above are not very selective, and foreign substances with structural similarities to endogenous molecules have the potential to be transported by means of these mechanisms. There is a suggestion that, at least in some cases, ENPs may cross barriers through these mechanisms. ${ }^{[25]}$ Another mechanism through which ENPs may cross internal barriers (probably more relevant than passive or active transport) is endocytosis, an active cellular process employed for the uptake of large, polar molecules that cannot pass through the hydrophobic membrane of a cell. Although there are different patterns of endocytosis (extensively discussed elsewhere ${ }^{[26-28]}$ ) a common final

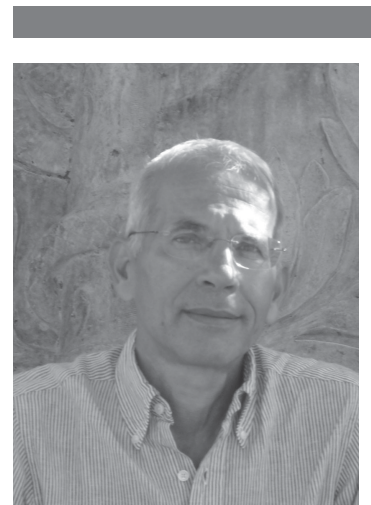

Antonio Pietroiusti, MD, is Assistant Professor of Occupational Medicine at the University of Rome "Tor Vergata". He is a partner in FP7-MARINA, a project focusing on reference methods for risk management of nanomaterials, in the COST action MODENA, aimed at quantitative nanostructure-toxicity-relationship (QNTR) modeling to facilitate risk assessment of novel nanomaterials, and NanoReg, focused on delineating regulatory measure for the use of nanomaterials. He co-edited the book Adverse Effects of Engineered Nanomaterials: Exposure, Toxicology, and Impact on Human Health with Prof. B. Fadeel from Karolinska Institutet and Prof. A. Shvedova from the National Institute for Occupational Safety and Health (NIOSH).

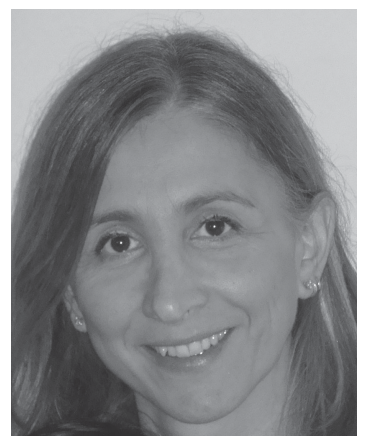

Luisa Campagnolo, $\mathrm{PhD}$, spent four years at the Scripps Research Institute of La Jolla (USA) and she is currently Assistant Professor of Histology and Embryology at the University of Rome "Tor Vergata" and is appointed Visiting Assistant Professor in the Dept. of Cell and Developmental Biology of Weill Cornell Medical College (New York). Over the last fifteen years she has developed a background in reproductive and developmental biology, and she has recently focused on nanotoxicology and reproductive and developmental related issues. Dr. Campagnolo is a member of FP7-MARINA, and a partner of the COST action MODENA and NanoReg and of several Italian National projects focused on nanotoxicology.

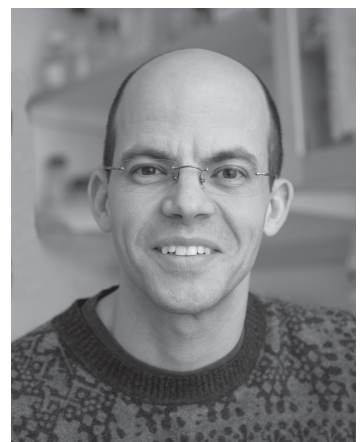

Bengt Fadeel, MD, PhD, is Head of the Division of Molecular Toxicology and Vice Chairman of the Institute of Environmental Medicine at Karolinska Institutet in Stockholm. He is Professor of Medical Inflammation Research at Karolinska Institutet and Adjunct Professor of Environmental and Occupational Health at the University of Pittsburgh, Pittsburgh, PA. He coordinated FP7-NANOMMUNE (on hazardous effects of nanomaterials on the immune system), and he is a current partner in FP7-MARINA, a project dealing with reference methods for risk management of nanomaterials. $\mathrm{He}$ is also a partner of FP7-NANOSOLUTIONS and NanoReg and the COST action MODENA.

pathway is the invagination of the cell membrane around the molecule deposited on the surface, with its subsequent inclusion into the cytoplasm of the cell. The frequent finding of ENPs within intracellular vesicles provides indirect evidence for this mechanism. ${ }^{[21,28]}$ Specific mechanisms of interaction between ENPs and each internal barrier are reported below.

\subsection{Blood-Brain Barrier}

The brain is supplied with an extensive network of fine blood vessels (capillaries). The endothelial cells of these 


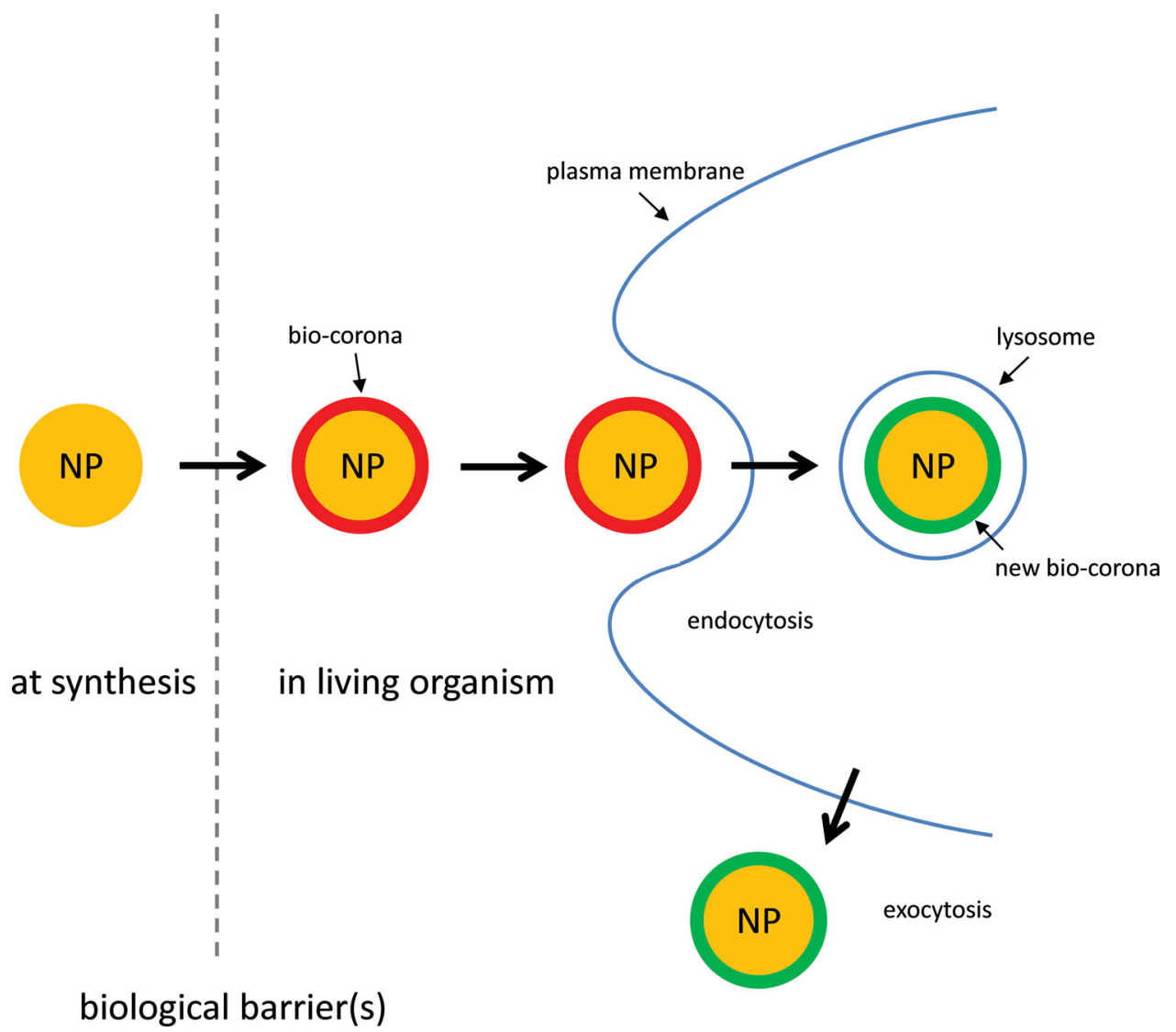

Figure 1. Schematic representation of the dynamic nature of the bio-corona on nanoparticle surfaces. Pristine surfaces of nanoparticles (NPs) are rapidly covered with biomolecules (proteins, lipids, etc.) as they enter into a biological compartment and the bio-corona may differ depending on the portal of entry (for instance, via the lungs, or the gastrointestinal tract); the bio-corona may undergo dynamic changes following endocytosis into cells and may undergo further changes upon exocytosis.

vessels, differently from other vessels, are connected each other by tight junctions made by special protein complexes, and lack the fenestrations typical of other endothelia. This fact strongly limits the influx into the brain of substances travelling in the systemic circulation. Other cells, such as astrocytes and pericytes, and the extracellular matrix support the primary role of endothelial cells in their barrier function, forming a highly efficient filter which protects the health and function of the central nervous system from external interferences. ${ }^{[29]}$ Further support to the BBB is given by the efflux transport system, which rapidly eliminates xenobiotics from the central nervous system (CNS) ${ }^{[30]}$ These characteristics strongly influence the translocation of ENPs into the brain, and explain their differential uptake in brain and peripheral organs, as recently discussed by Boyes et al. ${ }^{[31]}$

\subsection{Blood-Testis Barrier}

Maturation of male germ cells (spermatogenesis) occurs inside well circumscribed compartments, the seminiferous tubules, and is protected by Sertoli cells, which form the BTB. Such barrier is fundamental in blocking harmuful substances from reaching the male germ cells. BTB is one of the tightest blood-tissue barriers in mammalians. In fact, unlike the BBB, which constitute almost exclusively tight junctions between endothelial cells, in the BTB Sertoli's cells are joined by additional junctions such as basal ectoplasmic specializations, gap junctions, and desmosome-like junctions. ${ }^{[32]}$ Similarly to BBB, influx and efflux pumps regulate the rate at which allowed substances cross the barrier in both ways. It has been proposed that the release of inflammatory cytokines induced by ENPs may cause reduced testosterone production by Leydig cells; since testosterone is one factor strengthening the integrity of the BTB, this fact may cause weakening of the barrier, with consequent crossing of ENPs. ${ }^{[33]}$

\subsection{Placental Barrier}

The placenta is a peculiar anatomical barrier, since it is formed and functions only for a limited period of time, the 9 months of pregnancy in humans, along which its barrier properties change. Notably, both the fetus and the mother concur to placenta formation, and thus disorders affecting one of the two during the early stages of such formation may cause maldevelopment of the placenta itself, causing further adverse effects on the two, but in particular on the fetus, which is totally dependent on this organ for nutrition and gas exchange. In normal placental development of humans, the 
barrier has different thickness and permeability along pregnancy, being thicker and less permeable during the first trimester, and thinner and more permeable during the last three months. Thus, the chance for exogenous substances, including ENPs, to cross the placenta is higher during the third trimester of pregnancy. On the other hand, administration of potentially injurious agents at very early stages of pregnancy (eg. soon after implantation of the fertilized oocyte, when the placenta is not yet fully developed), may cause structural and functional alterations of the organ. There is indirect evidence that administration of some ENPs at this stage may cause severe damage to the placenta, associated with high rate of miscarriages and embryo malformations. ${ }^{[34]}$ We have obtained evidence, using fluorescently labelled single walled carbon nanotubes (SWCNTs) that these ENPs may reach the site of implantation before the complete development of the placenta has occurred (unpublished data), thus suggesting that a direct effect on the embryo at these very early stages may be the cause of both placental lesions and adverse fetal events.

In discussing the interactions of ENPs with internal barriers, we will discuss the $\mathrm{BBB}$ and $\mathrm{BTB}$ together, whereas the placental barrier will be treated separately, given the peculiar nature of this barrier.

\section{The Blood-Brain Barrier and the Blood- Testis Barrier}

\subsection{Translocation After Oral/Lung Exposure}

Most experimental data support the hypothesis that ENPs may cross internal barriers through any route of administration: pulmonary, gastrointestinal, intravenous, intraperitoneal and subcutaneous, after single or multiple exposures. Studies showing translocation after lung or oral exposure are summarized in Table 1. We have chosen to separate these exposure routes from parenteral routes because expected exposure in workers or consumer is expected to occur through these and also because, following interaction with peripheral blood,
ENPs may undergo transformations, which may in turn influence their translocation through the secondary (internal) barriers. It is evident that these possible changes are overlooked in the case of intravenous, intraperitoneal or subcutaneous injection, due to the deliberate circumvention of the primary barriers.

Of course, before interacting with internal barriers, ENPs should cross the alveolar-capillary barrier (after inhalation) and the gastro-intestinal barrier (after ingestion). The pattern of interactions of ENPs with the gastro-intestinal barrier is still poorly studied. ${ }^{[35]}$ On the contrary, some data are available on the alveolar capillary barrier, in particular from studies in rodents, suggesting that ENP interaction with surfactant lipids and proteins is crucial for their translocation through the barrier. This mechanism appears restricted to micro-sized particles, which are rapidly taken up by alveolar macrophages, whereas phagocytosis is much less efficient for ENPs thus making it possible for (small amounts) of nanosized particles to escape into the systemic circulation with accumulation in secondary organs (for an excellent discussion of biokinetics of inhaled particles of different sizes, see ref. [36] and [37]).

One oral study ${ }^{[38]}$ provided indication that lysosomes are the 'pharmacological target organelle' of SWCNTs whereas mitochondrial toxicity is seen at higher doses (Figure 2). The study is paradigmatic of the dual nature of ENPs: beyond the daily dose of $300 \mu \mathrm{g} / \mathrm{kg}$ a clear neurotoxicity was recorded, likely due to mitochondrial damage in affected cells. However, in the dose range of $5-300 \mu \mathrm{g} / \mathrm{kg}$, it was possible to take advantage of the carrier properties of the ENP: at these doses, SWCNTs were loaded with acetylcholine, a drug unable to cross $\mathrm{BBB}$, and the compositum was administered by gastro-gavage to mice with experimentally-induced Alzheimer's disease. There was an impressive dose-related recovery of learning activity in treated mice, whereas animals exposed to SWCNTs or to acetylcholine alone did not show any improvement.

The data reported in Table 1 clearly indicate that translocation through the BBB and BTB is possible for several

Table 1. Studies showing ENP translocation through secondary barriers after lung or oral exposure. ENPs are listed according to the administered dose, starting from the lowest one. Inhalation studies regarding ENP accumulation in the brain have not been included, since in this case direct access to the brain through the nerve endings in the nasal mucosa is possible. ${ }^{[47]}$

\begin{tabular}{|c|c|c|c|c|c|c|}
\hline ENP & LED $[\mu \mathrm{g} / \mathrm{kg}]$ & HND $[\mu \mathrm{g} / \mathrm{kg}]$ & Route & Target & Detection & Ref \\
\hline $\mathrm{Au}$ & $4(S)$ & Not evaluated & Intra-tracheal & Brain & Radioanalysis & [23] \\
\hline $\mathrm{CeO}_{2}$ & $1000(\mathrm{~S})$ & Not evaluated & $\mathrm{Gl}$ & Brain, testes & Radioanalysis & [53] \\
\hline $\mathrm{CeO}_{2}$ & $1000(\mathrm{~S})$ & Not evaluated & Intra-tracheal & Brain, testes & Radioanalysis & [53] \\
\hline $\mathrm{Ag}$ & $14000(C)$ & Not evaluated & $\mathrm{Gl}$ & Brain, testes & ICP-MS & [39] \\
\hline $\mathrm{Fe}_{2} \mathrm{O}_{3}$ & $16000(S)$ & Not evaluated & Intra-tracheal & Brain, testes & Radioanalysis & [46] \\
\hline $\mathrm{TiO}_{2}$ & $300000(C)$ & Not evaluated & $\mathrm{Gl}$ & Brain & ICP-MS & {$[61]$} \\
\hline SWCNTS & $500000(\mathrm{C})$ & $50000(C)$ & $\mathrm{Gl}$ & Brain & Qualitative & [38] \\
\hline $\mathrm{Ag}$ & $2730000(C)$ & Not evaluated & $\mathrm{Gl}$ & Brain, testes & AAS & {$[40]$} \\
\hline $\mathrm{Fe}_{3} \mathrm{O}_{4}$ & N.A. & Not evaluated & Inhalation & Testes & Qualitative & [105] \\
\hline
\end{tabular}

ENP = engineered nanoparticle; $L E D=$ lower effective dose; $\mathrm{HND}=$ higher non effective dose; $\mathrm{S}=$ single dose; $\mathrm{C}=$ cumulative dose; $\mathrm{GI}=$ gastrointestinal; $\mathrm{N} . \mathrm{A} .=$ not applicable; ICP-MS: inductively coupled-mass spectroscopy. 

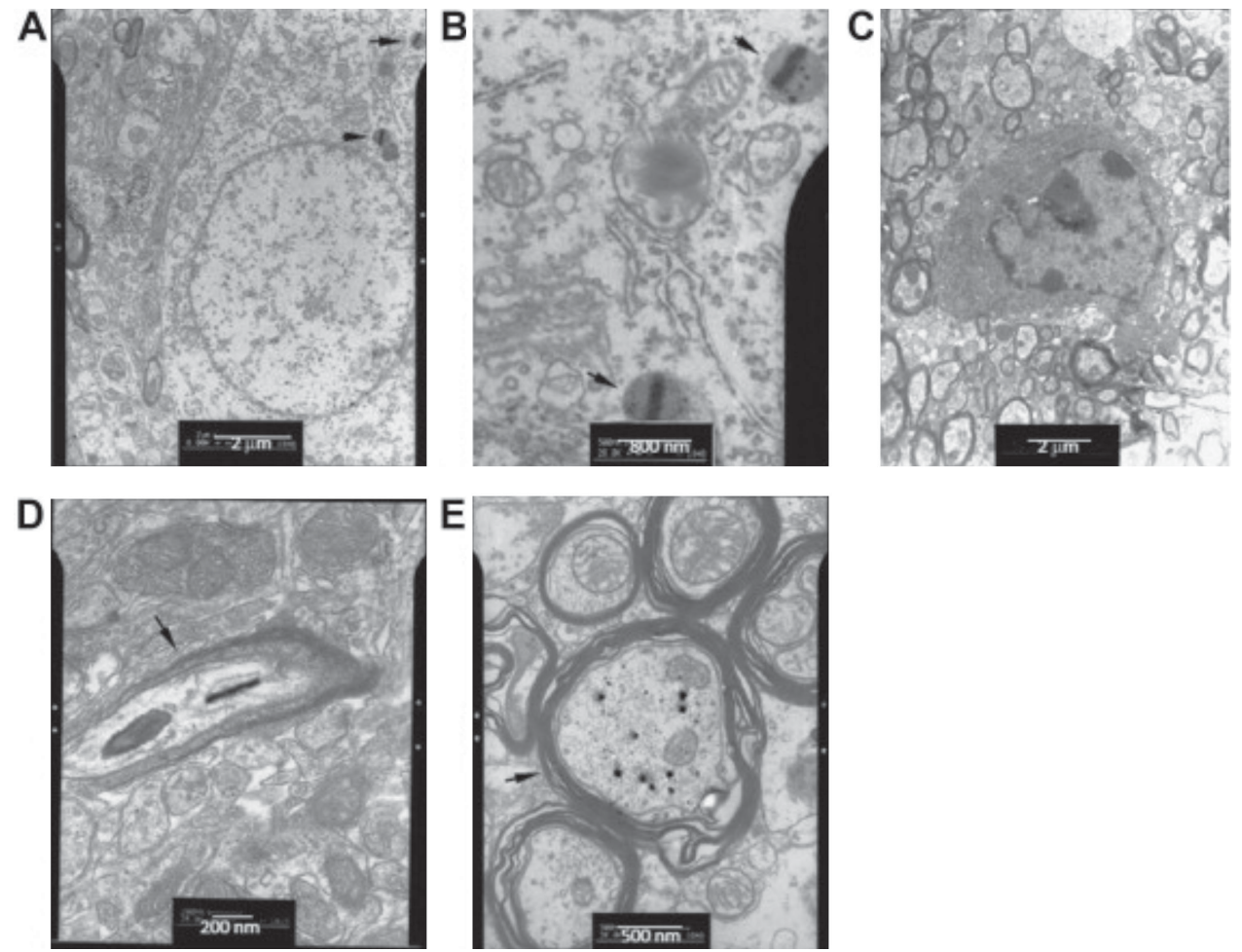

Figure 2. The cell distribution of single-walled carbon nanotubes (SWCNTS) in mouse brain examined by transmission electron microscopy after oral administration. (A) A neuron containing SWCNTs (arrowheads); (B) SWCNTs in two lysosomes indicated by arrows. (C) A glial cell containing no SWCNTs. (D) Section parallel to the longitudinal axis of one neurite, which was confirmed by the sheath (arrowhead). SWCNT is fiberlike. (E) Cross section of neurite, which was confirmed by the sheath (arrowhead). SWCNTs are dotlike. Reproduced with permission. ${ }^{[38]}$ Copyright 2010, Elsevier.

ENPs after exposure through the most plausible routes in humans. The extent of translocation, expressed as percentage of the administered dose is seemingly quite low, ranging from $0.00006 \%$ to $0.03 \% .{ }^{[39,40]}$ This means that the intact bloodbrain barrier greatly limits or prevents such translocation. However, it has been calculated that the accumulation of $1 \mathrm{ng} / \mathrm{g}$ of tissue of ENP with a size of $2 \mathrm{~nm}$ in a given organ implies the presence of a number of ENPs exceeding the number of cells in that organ by a factor of thousand. ${ }^{[25]}$ In the vast majority of studies performing a quantitative evaluation of the transferred amount of ENPs this threshold is largely exceeded. In addition, it should be considered that the percentage of translocation is similar in single and multiple exposure studies; however, in sub-chronic studies, the cumulative dose is much higher. Since chronic low grade exposure is predicted in humans, these data may be of concern for human health.

An important feature of the vast majority of the reported studies (Table 1) is that they did not search for the dose not crossing the barrier(s). So there are no indications on how much the tested doses exceed those which might be considered safe for human exposure. This information, however, is crucial for a better understanding of the potential risk for human health posed by ENPs. Although studies assessing the effect on embryo and offspring after lung or oral exposure of pregnant animals are available (discussed below), they are focused on the occurrence of damage, and analysis of possible translocation is not performed, except in one case, ${ }^{[41]}$ in which the presence of CdO NPs in the placenta, but not in the embryo, after exposure by inhalation was demonstrated. Of note, the latter study showed substantial embryo damage, thus suggesting that damage to organs protected by these barriers may arise through indirect mechanisms, one of which may be represented by injury to the barrier itself (in this case gross abnormalities of the placenta were observed). In fact, oral exposure to polystyrene nanoparticles was reported to influence iron uptake in in vivo chicken intestinal loop model and high doses of the model nanoparticle cause remodelling of the intestinal villi. ${ }^{[1]}$

Some oral/lung studies do not show translocation of ENPs, even at very high doses. This is the case, for example, of $\mathrm{ZnO}$ NPs, which did not show any crossing of the BBB after gastrointestinal exposure up at a cumulative dose of $12000000 \mu \mathrm{g} / \mathrm{kg}$. ${ }^{42]}$ The analysis of brain tissue did not show evidence of lipid peroxidation, which was observed in organs in which ENPs accumulated. Although this finding does not exclude possible brain injury in extreme conditions, transposition of these doses to predictable human exposure scenarios seem highly improbable, and therefore these data suggest that some ENPs, like ZnO NPs, may be intrinsically safe for organs protected by internal barriers. This fact is obviously overlooked when in vitro studies of $\mathrm{ZnO}$ are performed in which model cell lines are directly exposed to $\mathrm{ZnO} \mathrm{NPs}^{[43,44]}$ A systematic search for the identification of potentially safe and potentially harmful ENPs should be performed. 
Another lesson from lung/oral exposure studies concerns the importance of detecting ENPs in organs protected by internal barriers even at very low amounts since the use of more or less sensitive methods may strongly influence the interpretation of the experiment. As an example, in a study on translocation of $\mathrm{TiO}_{2}$ NPs into the brain it was concluded that "there was no translocation of inhaled material into the brain"; ${ }^{[45]}$ however, the detection limit for the assessment of ENP translocation was $500 \mathrm{ng} /$ organ. In contrast, in a more recent study, Schleh et al. ${ }^{[23]}$ concluded that "there was an enhanced accumulation of NPs in the brain", potentially harmful for human health; however, in this case, the detection limit was less than $1 \mathrm{ng} /$ organ, and the detected accumulation was about 2 ng. Highly sensitive methods, like radioanalysis, are probably the most appropriate in this particular context.

\subsection{Role of the Exposure Route in the Crossing of the BBB}

There are indications that prior residence of ENPs in the pulmonary environment may modify the pattern of adsorbed proteins onto their surface once they reach the systemic circulation. ${ }^{[10-12]}$ This event may, in turn, influence the biodistribution and toxicity of these ENPs. Similarly, recent evidence suggests that transit through the gastro-intestinal tract may strongly influence the access of ENPs into the brain. In an initial intravenous study it was reported a size-regulated access of gold NPs into the brain, with $1.4 \mathrm{~nm}$ NPs being translocated ten times more than $18 \mathrm{~nm}$ gold NPs. ${ }^{[46]}$ In a subsequent study, under the same experimental conditions, the authors observed that after gastro-intestinal exposure to the same ENPs, the blood concentration of $1.4 \mathrm{~nm}$ gold $\mathrm{NP}$ was 3.8 times higher than that of $18 \mathrm{~nm}$ gold NP; ${ }^{[23]}$ thus, on the basis of the data of the previous intravenous experiment, it would had been expected an almost 40 times higher intra-cerebral access of $1.4 \mathrm{~nm}$ ENPs in comparison to $18 \mathrm{~nm}$ ENPs. Surprisingly, the opposite was true, with $18 \mathrm{~nm}$ ENPs showing a rate of access into the brain 3 to 4 times higher than $1.4 \mathrm{~nm}$ ENPs. These data suggest that previous exposure to the gastrointestinal environment may strongly influence the rate of translocation through the BBB.

Intravenous studies, even at doses similar to those predictable after the passage of ENPs through the primary barriers, may be unreliable to represent the situation occurring after such exposure, and may give misleading information about their potential harmful effects. In fact, physico-chemical changes occurring during the residence of ENPs in the lung or in the gastrointestinal tract may dramatically change their ability to cross internal barrier. A related issue is the need for more careful studies of the molecules adsorbed on the surface on ENPs during their transit through the gastro-intestinal tract and the identification of the key factors affecting their translocation through the internal barriers. ${ }^{[35]}$

Interestingly, animal studies have shown that the BBB may be circumvented under certain circumstances. Hence, Elder et al. ${ }^{[4]}$ reported that inhaled manganese nanoparticles are transported in a retrograde manner via the olfactory nerve to the brain in rats and that this can result in inflammatory changes. These findings have been extended by subsequent reports evaluating other ENPs. Studies on $\mathrm{TiO}_{2}$ nanoparticles have in fact shown that neural transport might be influenced by size, shape and surface coating, ${ }^{[48]}$ and that the hippocampus may be the main target ${ }^{[49]}$ (Figure 3). The existence of an olfactory bulb-brain translocation pathway after intranasal instillation has been detected also for $\mathrm{Cu}$ nanoparticles, ${ }^{[50]}$ which caused perturbations in neurotransmitter secretion. A recent inhalation study showed evidence of brain translocation through the nasal route in rats for airborne $\mathrm{ZnO}$ nanoparticles. ${ }^{[51]}$ The putative mechanisms of the neural transport of ENPs have been reviewed by Oberdörster et al.;52] however, the relevance of this exposure route for humans remains to be substantiated. Nevertheless, there is anecdotal evidence of the presence of colloidal gold nanoparticles lodged in the brain of deceased glassblowers.

\subsection{Are there Differences Between the BBB and BTB?}

The ability of ENPs to cross the BBB and BTB has been concomitantly evaluated in some studies regarding nanoceria, gold NPs, $\mathrm{Fe}_{2} \mathrm{O}_{3} \mathrm{NPs}$, and silver NPs, ${ }^{[39,40,53-57]}$ and data are thus available for comparison (Figure 4). In these studies, the amount of ENP per g/tissue is similar for testes and brain in evaluations performed within 15 days from the start of the experiment; however, after this time there is a marked tendency to a relative increase in testis accumulation in comparison to brain. This finding suggests that BTB is less efficient than $\mathrm{BBB}$ in the case of prolonged challenge with ENPs, possibly due to a loss of the anatomical integrity and/or to a loss of efficiency of extruding mechanisms. In the above mentioned studies, no overt histological damage to brain or testes was found. However, genetic damage and increased apoptosis of spermatids in the absence of brain damage has been recently reported after daily exposure for seven days to $\mathrm{TiO}_{2}$ NPs by oral gavage. ${ }^{[58]}$

Overall, evaluation at different time-points, extended over months is needed for understanding the effects of ENPs on organs protected by internal barriers. In the case of the brain, after a single exposure a tendency to early accumulation is observed, followed by a decrease over time; differently, in the testes, despite an early accumulation similar to the brain, a further increase in the following weeks is detected. For some ENPs, no accumulation in testes is observed within the first days after exposure, but a significant amount of ENPs is demonstrated after 1 month from the exposure and persisting in the following weeks. ${ }^{[56]}$ In the case of subacute or subchronic exposure the accumulation of ENPs is more marked in testes than in brain, and possibly the bio-corona may play an important role for the organspecific distribution of ENPs. ${ }^{[59]}$

\subsection{Damage to the Brain and Testis after Exposure to ENPs}

As reported above, accurate quantitative studies are the most appropriate for evaluating the crossing of internal barriers by ENPs. These studies generally imply the destruction of tissue, and concomitant evaluation of tissue damage is therefore 
Cerebral Cortex
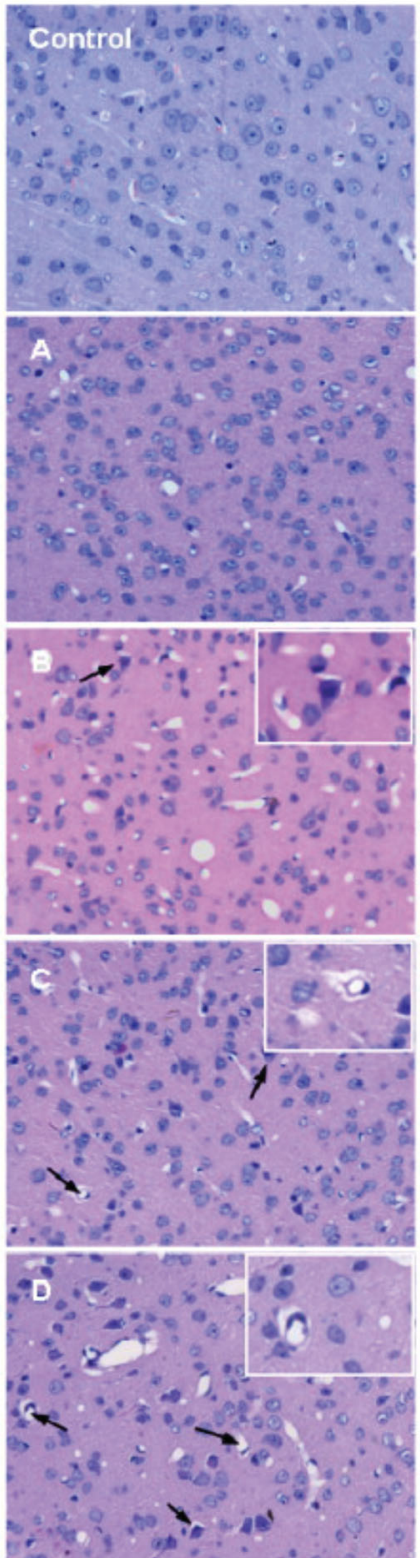

Hippocampus CA1
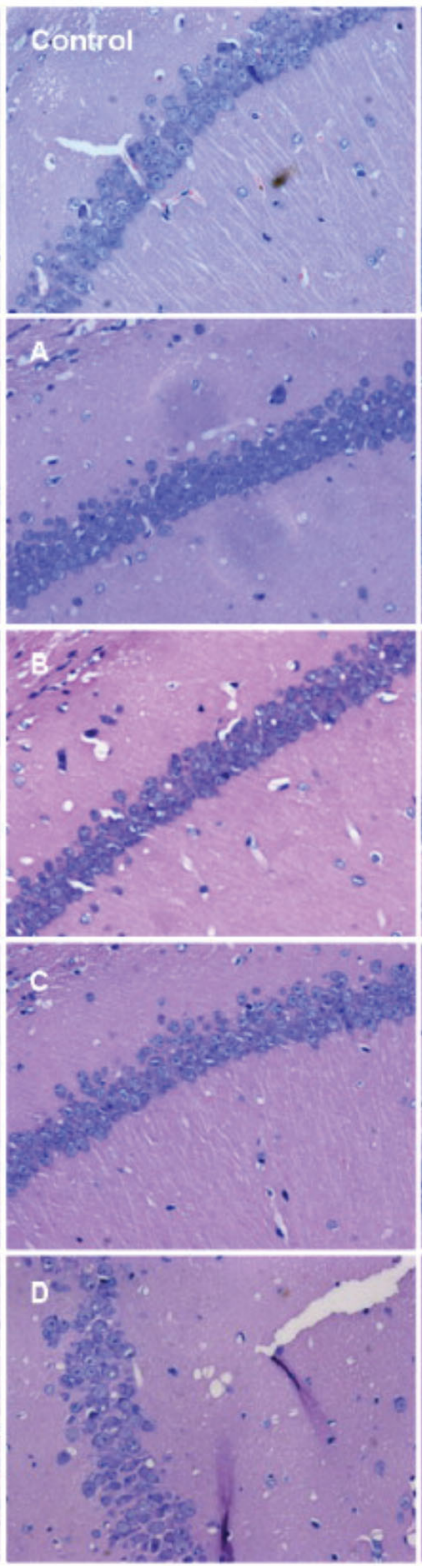

Hippocampus DG
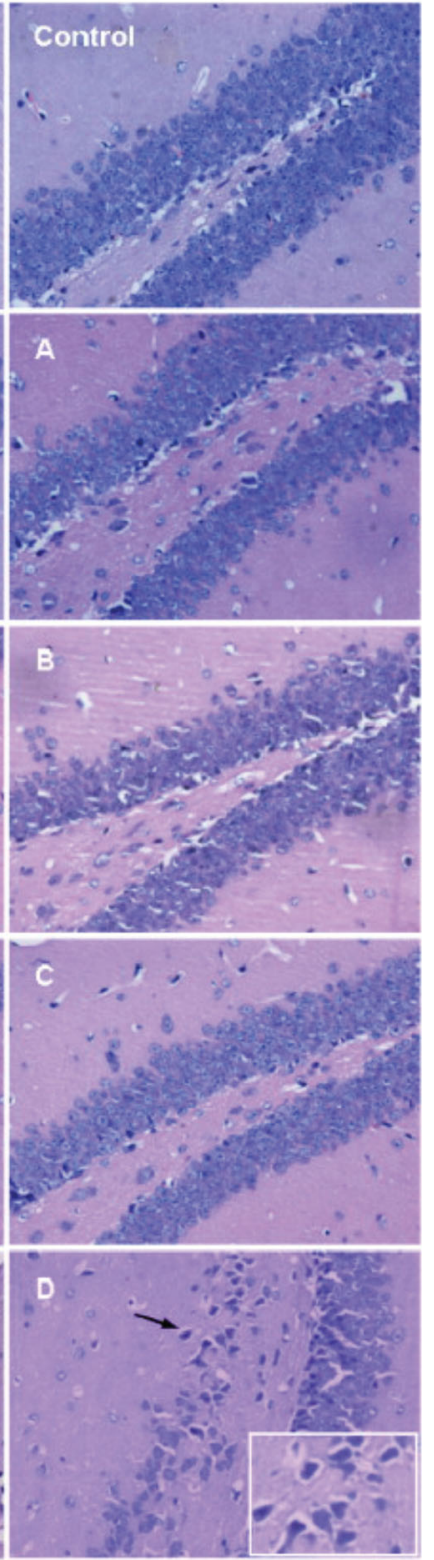

Figure 3. Morphological changes of neurons in the HE stained brain tissue sections of the cerebral cortex and hippocampus (CA1 and DG) in mice after intranasal instillation of different TiO2 particles (samples A, B, C and D). Normal pyramidal cells showed round and pale stained nuclei, whereas dying or dead cells showed pyknotic nuclei. Normal structure of pyramidal cells has round/oval and pale stained nuclei as well as clear nucleolus. Damaged neurons have shrunken cell bodies, deeply stained pyknotic nucleus with triangular or elongated profile and the nucleolus disappeared, as well as the widened gap between the nuclei and the cell membrane. Arrows indicate the damaged neurons. Reproduced with permission. ${ }^{[48]}$ Copyright 2011, Elsevier.

often lacking. However, in some cases concomitant data on crossing of the barrier and possible damage induced by ENPs on the inner organs are available.

As done for translocation, we will mainly focus on lung and gastro-intestinal routes of exposure to ENPs, given their relevance for human exposure. The data shown in Table 2 highlight the wide range of doses at which ENPs administered through the lung or the gastrointestinal route may cause damage; similarly, the severity and type of detected damage may differ in various reports, ranging from mild functional effects, ${ }^{[60]}$ to severe histological damage. ${ }^{[61,62]}$

\subsection{The Relevance of Parenteral Studies}

The administration of ENPs via the parenteral route circumvents the filter action of the pulmonary and gastrointestinal primary barriers and therefore does not provide information 


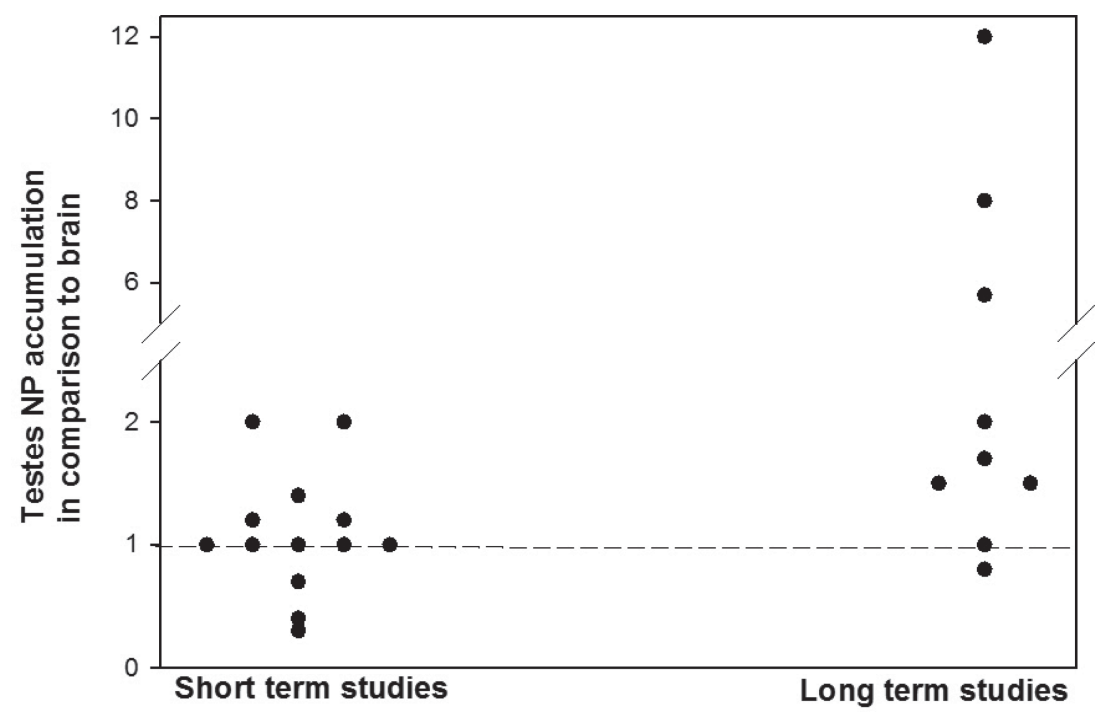

Figure 4. Pattern of ENP retention in testes relative to brain. Assessments performed within 15 days after the administration of ENPs are shown on the left side, whereas evaluations made at later time-points are on the right. Both short and long term studies refer to nanoceria, gold NPs, $\mathrm{Fe}_{2} \mathrm{O}_{3} \mathrm{NPs}$ and silver NPs (data taken from ref. [39,40,53-57]). This analysis reveals a relative increase in testis accumulation in comparison to brain following long-term exposure suggesting that the blood-testis barrier (BTB) is less efficient than the blood-brain barrier (BBB) in cases of prolonged challenge with ENPs.

of direct relevance from a toxicological perspective: the parenteral exposure route is in fact highly unusual for worker or consumer exposure; the dose is generally unrealistic (it should be considered that less than $1 \%$ of the administered dose is generally absorbed after lung or gastrointestinal exposure), and it is administered as a bolus (in place of the relatively slow pattern of absorption through the gastrointestinal and respiratory route). In addition, the nano-bio interface, determined by the interaction of ENPs with body fluids, is different after direct access into the systemic circulation than after previous interaction with gastro-intestinal and lung fluids. Nevertheless, the information obtained in such studies may be of indirect help in understanding the relevance of physico-chemical modifications of ENPs interacting with primary barriers and their subsequent interaction with secondary barriers, as illustrated above in the case of translocation of gold NPs after exposure through the gastrointestinal route. Furthermore, given the generally very high doses used in intravenous experiments, the absence of any evidence of translocation across internal barriers even in this extreme context, may allow one to confidently draw conclusions regarding the safety of the tested ENPs: this is the case of nanoceria which after short and long term assessments following single, ${ }^{[57,63]}$ or multiple ${ }^{[64]}$ high dose administrations showed minimal brain accumulation and absence of toxicity.

In some cases parenteral studies may complement oral/lung exposure data, and give indications for further studies. For example, only low dose, single exposure data are available for gold NPs after exposure through the oral and pulmonary route. The first question is: may substantial amounts of gold NPs, achievable after chronic exposure, accumulate and/or induce damage to the central nervous system? After a single intraperitoneal dose of $1900 \mu \mathrm{g} / \mathrm{kg}$ there was an impairment of cognition in mice $^{[65]}$ associated with substantial translocation of ENPs and damage to the brain, especially to the hippocampus. This

Table 2. Studies showing damage of organs protected by secondary barriers after lung or oral exposure. ENPs are listed according to the administered dose, starting from the lowest one. Data on inhalation studies are grouped at the end of the table and regard damage to the brain/testes of embryo or offspring after exposure of pregnant mothers.

\begin{tabular}{|c|c|c|c|c|c|}
\hline ENP & $\begin{array}{c}\text { LED } \\
{\left[\mu \mathrm{g} / \mathrm{kg} \text { or } \mu \mathrm{g} / \mathrm{m}^{3}\right]}\end{array}$ & $\begin{array}{c}\text { HND } \\
{\left[\mu \mathrm{g} / \mathrm{kg} \text { or } \mu \mathrm{g} / \mathrm{m}^{3}\right]}\end{array}$ & Route & Target & Ref \\
\hline CB & $370(C)$ & Not evaluated & Lung (IT) & Testis & {$[60]$} \\
\hline CB & 13334 (C) & Not evaluated & Lung (IT) & Testis* & [82] \\
\hline CB & $46608(C)$ & $9388(C)$ & Lung (IT) & Brain* & [79] \\
\hline $\mathrm{SiO}_{2}$ & $52500(C)$ & Not evaluated & Lung (IT) & Testis & [106] \\
\hline $\mathrm{TiO}_{2}$ & $300000(C)$ & Not evaluated & GI Tract & Brain & [61] \\
\hline $\mathrm{TiO}_{2}$ & $5000000(\mathrm{~S})$ & Not evaluated & GI Tract & Brain & {$[107]$} \\
\hline SWCNTS & $5600000(\mathrm{C})$ & $4200000(C)$ & GI Tract & Brain & [38] \\
\hline $\mathrm{TiO}_{2}$ & $7000000(C)$ & Not evaluated & GI Tract & Testis & [58] \\
\hline $\mathrm{CdO}$ & 2.5 h/day 230 per 12 days & $2.5 \mathrm{~h} /$ day 100 every other day per 12 days & Lung (I) & $\mathrm{Pl} /$ Embryo & [41] \\
\hline $\mathrm{TiO}_{2}$ & $1 \mathrm{~h} /$ day 42000 per 10 days & Not evaluated & Lung (I) & Brain* & [77] \\
\hline $\mathrm{SiO}_{2}$ & $\begin{array}{c}2 \text { h/day } 100000 \text { every other day } \\
\text { per } 65 \text { days }\end{array}$ & Not evaluated & Lung (I) & Testis* & [62] \\
\hline
\end{tabular}

$\mathrm{ENP}=$ engineered nanoparticle; $\mathrm{LED}=$ lower effective dose; $\mathrm{HND}=$ higher non effective dose; $\mathrm{CB}=$ carbon black; $\mathrm{S}=$ single dose; $\mathrm{C}=$ cumulative dose; $\mathrm{Gl}=$ gastrointestinal; $\mathrm{IT}=$ intra-tracheal; I = Inhalation; * = detected in offspring; $\mathrm{Pl}=$ placenta 
finding highlights therefore the need for chronic exposure studies through the respiratory and gastrointestinal routes to evaluate whether a similar effect may be replicated.

Similarly, there is evidence in the case of Ag NPs of substantial brain accumulation after sub-acute ${ }^{[39]}$ or subchronic $^{[40]}$ oral exposure, but no data on possible brain damage. Ag ENPs injected subcutaneously caused BBB damage associated with neuronal degeneration ${ }^{[66]}$ highlighting the potential of this ENP not only to cross the intact $\mathrm{BBB}$, but also to induce damage of the barrier at high doses.

Support for the notion that damage of the BBB is a potential pathogenetic mechanism of brain injury after exposure to ENPs is given by a study on $\mathrm{Al}_{2} \mathrm{O}_{3}$ NPs, showing fragmentation and disruption of the integrity of the $\mathrm{BBB}$ tight junction proteins after intravenous exposure, although at very high doses. ${ }^{[67]}$ Considering the use of $\mathrm{Al}_{2} \mathrm{O}_{3}$ NPs both in occupational and consumer settings, ${ }^{[68]}$ appropriate studies assessing the effect on the brain of this ENP after oral or lung exposure are warranted.

As far as parenteral studies on the interaction of ENPs with BTB are concerned, evaluation of testis accumulation/ damage after intravenous or intraperitoneal administration of ENPs is available for nanoceria, ${ }^{[57]}$ gold NPs, ${ }^{[55,56]}$ silica NPs,${ }^{[69]}$ multi-walled CNTs (MWCNTs), ${ }^{[70]}$ and $\mathrm{TiO}_{2} \mathrm{NPs}^{\left[{ }^{[71]}\right.}$ In all cases, crossing of the BTB was observed. Three studies, regarding $\mathrm{MWCNTS}^{[70]}$ nanoceria ${ }^{[57]}$ and gold NPs, ${ }^{[56]}$ had a follow-up of 60 and 90 days, respectively. Interestingly, for nanoceria and gold accumulation in testes was higher at the end of the follow-up than after 30 days. This confirms the tendency to late accumulation of ENPs in testes observed in studies of oral and lung exposure, and suggests that the filter function of BTB is probably less efficient after long term exposure to ENPs. This hypothesis is in accordance with the suggested mechanism of crossing of the BTB by ENPs, resulting in weakening of the integrity of the barrier. ${ }^{[33]}$

Evidence of testis damage was reported after intravenous administration of 5 doses of carboxylated MWCNTs over 13 days $^{[70]}$ and after 5 intraperitoneal injections of $\mathrm{TiO}_{2}$ NPs over 10 days. ${ }^{[71]}$ In the case of MWCNTs, damage was almost completely reversed after 60 days; however, it remains unknown whether a more prolonged exposure to CNTs may lead to irreversible testis damage.

As far as the damage observed after intraperitoneal $\mathrm{TiO}_{2}$ injection is concerned, it is in accordance with the data observed after oral exposure, ${ }^{[58]}$ and therefore the findings of the intraperitoneal study give further support to the suggestion that this ENP should be regarded as potentially toxic for the male reproductive organs.

\section{The Placental Barrier}

In the following section, a survey of studies on the crossing of the placenta and damage to the embryo is presented for a better understanding of the interaction of ENPs with this important biological barrier.

\subsection{Silica NPs}

Yamashita et al. performed studies in which $70 \mathrm{~nm}$ silica NPs were administered to pregnant mice at doses of 16000,24000 or $32000 \mu \mathrm{g} / \mathrm{kg}$ on two consecutive days, at the gestational age of 16 and 17 days. ${ }^{[72]}$ Animals were sacrificed on day 18. Qualitative methods (TEM, and fluorescence microscopy for fluorescently labelled NPs) were used to assess NP distribution. No transplacental crossing or damage were observed for the two lower doses (at least with the detection methods exploited), whereas at the highest dose transplacental crossing (with localization of NPs in the brain and liver of the fetus), histological placental damage, and fetal growth restriction were observed. These findings may have implications for the possible use of silica NPs as nanocarriers for drug delivery, but are reassuring from a toxicological point of view, showing that even the huge dose of $48000 \mu \mathrm{g} / \mathrm{kg}$ of silica NPs given intravenously does not cause harm to the fetus, at least when exposure occurs late in gestation. However, it is important to recall that different effects might be expected when exposure occurs at earlier stages.

\subsection{Titanium Dioxide NPs}

In the above cited study on silica $\mathrm{NPs}, \mathrm{TiO}_{2} \mathrm{NPs}$ (size $63 \mathrm{~nm}$ ) were also used, at the same amounts, and the same doserelated effects ${ }^{[72]}$ on the placenta and fetus were observed.

Toxicity to the central nervous system and to the testes in male offspring, associated with the presence of $\mathrm{TiO}_{2} \mathrm{NPs}$ $(25-70 \mathrm{~nm})$ in the brain and testes, were reported after repeated subcutaneous injections $(3333 \mu \mathrm{g} / \mathrm{kg}$ for each injection) to the pregnant mothers on day $3,7,10$, and 14 of gestation. ${ }^{[73]}$ Male offspring were sacrificed at day 4 or at week 6 of age. A qualitative assessment (TEM and EDS) of the ENPs revealed their presence in both the brain and testes, associated with damage to the seminiferous tubules and altered function of sperm cells in the testes, and with apoptosis of neural cells and occlusion of small vessels in the brain. Although the authors interpret their findings as evidence of transplacental passage of the injected $\mathrm{TiO}_{2} \mathrm{NPs}$, it should be noted that the first subcutaneous injections on day 3 and 7 were performed at a time when a true placenta has not yet developed in mice, and therefore ENPs might have more easy access to the fetal tissues, where the damage is probably further amplified by the incomplete development of BBB and BTB. Of note, $\mathrm{TiO}_{2}$ NPs may cause damage to brain and testes also in adults. ${ }^{[71,74]}$

The same researchers performed other experiments with $\mathrm{TiO}_{2}$ NPs, with slightly different design and targets. Hence, they administered subcutaneously to mice the same amount of ENPs as in the previous study, on gestational days 6, 9, 12, 15, and 18 and performed neurochemical analysis of the brain of 6 week old male pups; they found increased levels of dopamine, compatible with alterations in motor and cognitive functions. ${ }^{[75]}$ In a third study, the authors evaluated in the brain of the offspring the effect of $\mathrm{TiO}_{2}$ on gene expression associated with apoptosis, brain development, oxidative stress, and with neurotransmitters and psychiatric diseases. ${ }^{[76]}$ Interestingly, these alterations were found both in embryos (at a developmental stage of 16 days) and in pups 2, 7, 14, and 21 days old.

Moderate neurobehavioural alterations in offspring at weeks $11-16$ of age were observed by other investigators 
exposing pregnant mice by inhalation $\left(1 \mathrm{~h} /\right.$ day to $42 \mathrm{mg} / \mathrm{m}^{3}$ aerosolized powder) to $21 \mathrm{~nm} \mathrm{TiO}_{2}$ NPs on gestation days $8-18 .{ }^{[77]}$

In addition to brain and testis, damage to the offspring has been also detected in other organs. Inhalation of $21 \mathrm{~nm} \mathrm{TiO}_{2}$ NPs ( $1 \mathrm{~h} /$ day to $42 \mathrm{mg} / \mathrm{m}^{3}$ aerosolized powder) during gestation days 8-18 was in fact associated with altered liver gene expression related to the retinoic acid signalling pathway in female offspring evaluated in post-natal days 2 and 22. ${ }^{[78]}$ However, the presence of $\mathrm{TiO}_{2}$ NPs was not assessed, so it is unclear if the observed effects are due to a direct or indirect action of the inhaled material.

\subsection{Carbon Black}

Carbon black is a well characterized carbonaceous core nanoparticle making it an attractive benchmark NP. Three studies have been performed by Danish researchers on the effects on the offspring of maternal pulmonary exposure to carbon black during pregnancy. In these studies, four intra-tracheal instillations, on gestational days $7,10,15$, and 18 were performed in pregnant mice by using carbon black (geometric mean size 64 $\mathrm{nm})$ at three different concentrations by instillation $(478 \mu \mathrm{g} /$ $\mathrm{kg}, 2347 \mu \mathrm{g} / \mathrm{kg}$, or $11652 \mu \mathrm{g} / \mathrm{kg}) .{ }^{[79-81]}$ In two studies, ${ }^{[80,81]}$ focusing on the liver, alteration of several biological pathways were observed, whereas in the third study, focusing on the brain, memory impairment was observed in female offspring of the highest exposure group. ${ }^{[79]}$ Interestingly, in one study a subgroup was exposed also by inhalation, ${ }^{[81]}$ and displayed a more marked liver damage, probably as a consequence of higher translocation of inhaled ENPs in comparison to those instilled. Of note, the dose used in the inhalation study corresponds to one-and-a-half days that Danish workers might experience at the time-weighted average occupational exposure limit $\left(3.5 \mathrm{mg} / \mathrm{m}^{3}\right.$ for carbon black), and are therefore of relevance from an occupational perspective.

Alterations of the reproductive function associated with pre-natal exposure of male mice have been also reported. Yoshida et al. administered intra-tracheally at gestation days 7 and 14, carbon black NPs (size $14 \mathrm{~nm}$ ) at the amount of $6667 \mu \mathrm{g} /$ $\mathrm{kg}$ for each instillation, and sacrificed male offspring at the age of 5,10 , or 15 weeks. ${ }^{[82]}$ The authors did not observe adverse effect on fetal growth, but detected testes lesions in the postnatal period, characterized by seminiferous tubule damage, decreased sperm production, and alterations in testosterone secretion, thus confirming that male reproductive apparatus is a privileged target in male animals exposed in utero.

\subsection{Gold NPs}

Gold nanoparticles are studied extensively for their promising biomedical applications. However, already 30 years ago, a study was published in which about $0.018 \%$ of the administered dose was detectable in the embryo, after the intravenous injection of $118 \mu \mathrm{g} / \mathrm{kg}$ of 5 radiolabelled gold NPs to pregnant rats at day 19 of gestation. ${ }^{[83]}$ A lower translocation rate was found for $30 \mathrm{~nm}$ gold NPs.
A size-related crossing was observed also in a more recent study performed in pregnant rats at near term, who received 1.4 or $18 \mathrm{~nm}$ radiolabelled gold NPs intravenously; 24 h later, particles were present in the placenta and embryo, however, translocation rate was much lower compared to the previous study, being $0.0006 \%$ of the injected dose. ${ }^{[84]}$

By contrast, no transplacental crossing was observed in mice injected with $2 \mathrm{~nm}$ gold NPs $(404 \mu \mathrm{g} / \mathrm{kg})$ or with $40 \mathrm{~nm}$ NPs $(1940 \mu \mathrm{g} / \mathrm{kg})$ at the gestational age of 16-18 days and sacrificed 24 h later. ${ }^{[85]}$ However, a relatively insensitive method of detection (autometallography) was employed in this study.

Taken together, these data indicate a relatively low rate of translocation of gold NPs through the placenta and confirm the size-related crossing of internal barriers seen for BBB and BTB. It would be important to know whether the degree of translocation may be different at earlier stages of pregnancy, and whether a longer time of contact associated with this exposure may lead to damage of the feto-placental unit, not tested in the above mentioned studies. Furthermore, it should also be tested whether the size-related crossing of the placenta observed with intravenous injection may be modified after oral exposure, as in the case of the BBB. ${ }^{[23]}$

\subsection{Fullerenes}

Interest in fullerenes is supported by their demonstrated antioxidant properties. However, in a pioneering study ${ }^{[86]}$ the intraperitoneal injection of 25000 to $137000 \mu \mathrm{g} / \mathrm{kg}$ of $2 \mathrm{~nm}$ fullerene at gestational day 10 , caused embryo malformations (at the lowest doses) or death (at the highest doses) 18 hours after the injection. At all doses, the ENPs were clearly distributed in the embryos, and clear damage of midbrain cells was observed.

More recently, radiolabelled $2 \mathrm{~nm}$ fullerenes were intravenously administered to pregnant rats on gestational day 15 at the dose of $300 \mu \mathrm{g} / \mathrm{kg}$. Animals were sacrificed $24 \mathrm{~h}$ later: $0.872 \%$ of the administered dose was recovered in fetuses ( $1.1 \%$ was detected in the placenta). Possible damage to the fetuses was, however, not assessed in this study. ${ }^{[87]}$

\subsection{Carbon Nanotubes}

Carbon nanotubes are produced in large quantities worldwide and are being applied in numerous sectors in society. ${ }^{[4]}$ However, the only available study in pregnant animals, performed by our group, shows that the intravenous injection of 3.3 to $1000 \mu \mathrm{g} / \mathrm{kg}$ of oxidized SWCNTs (diameter $1.8 \mathrm{~nm}$, length $0.37 \mu \mathrm{g})$ to pregnant mice at 5.5 days of gestation is associated with miscarriages (at the highest doses) and malformations (at the lower doses) in embryos observed 10 days later. Gross placental abnormalities were associated with embryo malformations, and there was evidence of oxidative stress in both embryos and placentas (Figure 5). Less pronounced alterations were seen with non oxidized nanomaterial. ${ }^{[34]}$ SWCNTs were not found in the placenta and fetuses, but this may be related to the high background level of carbon in tissues, to the low exposure doses and to the qualitative 

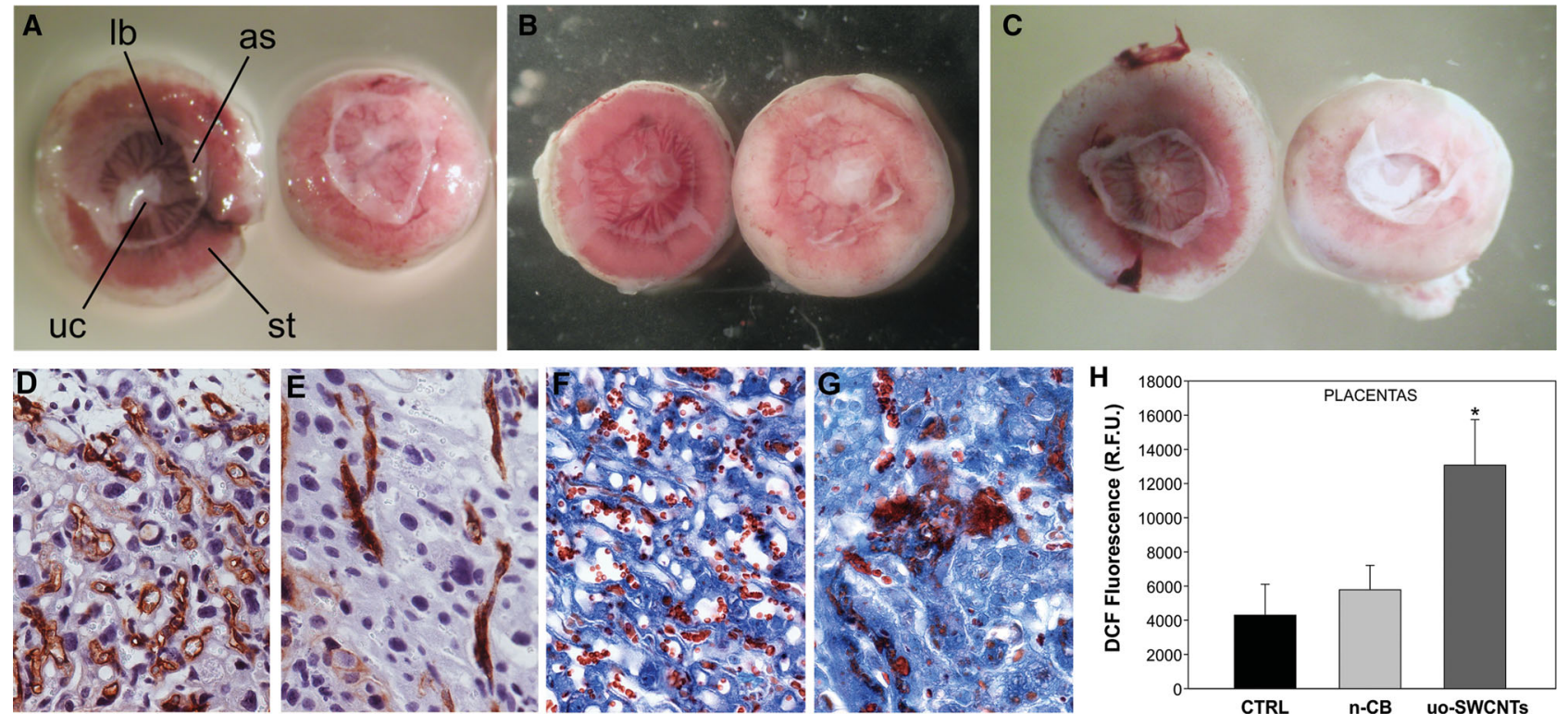

Figure 5. Macroscopic and microscopic analysis of placentas from normal and malformed fetuses and evaluation of oxidative stress. (A-C) Images of placentas from normal (left) and malformed (right) fetuses from (A) pristine, (B) oxidized, and (C) ultra oxidized SWCNT-treated mothers. The labyrinth layer appears disorganized in placentas from malformed fetuses. (D, E) Immuno-staining using anti-CD31 antibodies shows decreased vascularization in malformed placentas (E) compared to normal ones (D). (F, G) Azan-Mallory staining reveals the presence of fibrin deposition in abnormal placentas (G) that are not detected in normal samples (F). uc: umbilical cord attachment site; lb: labyrinth layer; as: amniotic sac residues; st: maternal spongiotrophoblast. (H) Oxidative stress appeared increased in placentas from mothers exposed to SWCNTs. Values are expressed as relative fluorescence units (RFU) normalized per milligram of protein. Statistical analysis was performed by the ANOVA test ( $p<0.01)$. Reproduced with permission. ${ }^{[34]}$ Copyright 2011, American Chemical Society.

method used to assess the presence of CNTs. The extremely low doses at which embryo malformations were observed in this study indicate the need for further evaluation of the possible embryotoxic effects of SWCNTs through the lung/oral route.

In a recent study, MWCNTs were administered by oral gavage to pregnant rats at daily doses of 4000, 200000 or $1000000 \mu \mathrm{g} / \mathrm{kg} /$ day for 13 days, starting from day 6 of gestation. ${ }^{[88]}$ At this time rats were sacrificed and fetuses examined. No gross abnormalities were detected. Given the huge doses employed in this study, it can be confidently concluded that oral exposure to MWCNTs may be considered safe for fetal development.

\subsection{Quantum Dots}

When injected intravenously to pregnant mice 1-5 days before delivery, substantial size-related fetal accumulation of quantum dots (QDs) was observed. ${ }^{\left[{ }^{89]}\right.}$ The QDs used in this study had a CdTe core and $\mathrm{Cd}$ accumulation in embryos up to $0.6 \%$ of the injected dose (670 or 1670 or $2670 \mu \mathrm{g} / \mathrm{kg}$ ) was observed. For comparison, CdSe/CdS/ZnS QDs administered to nonhuman primates (rhesus macaques) by intravenous injection elicited no toxicity but the initial dose of $\mathrm{Cd}$ remained in liver, spleen and kidneys after 90 days. ${ }^{[90]}$ In contrast, another recent study failed to show translocation of $\mathrm{Cd}$ to the fetus in pregnant mice exposed to inhalation of $230 \mu \mathrm{g} \mathrm{CdO} / \mathrm{m}^{3}$ starting from 4.5 days post coitus (dpc) through $16.5 \mathrm{dpc} .^{[41]}$ However, Cd was detected in the placenta, which appeared damaged, and in parallel decreased fetal length, as well as delayed neonatal growth, were observed.

These findings suggest that embryo alterations may be elicited by ENPs even in the absence of translocation through the placental barrier. If ENPs reach and damage the placenta, fetal alterations are generally unavoidable, due to the strict dependence of the fetus on the efficiency of the placenta for nourishment and gas exchange.

\subsection{Lessons from Studies on the Feto-Placenta Unit}

Can we draw any lessons from the abovementioned studies of NPs and the feto-placental unit? First, the placenta is a developing organ during pregnancy. In humans, its development starts soon after implantation, with the formation of the primitive placenta, leading to the definitive placenta at the end of the first trimester. The embryo surrounded by the primitive placenta is separated by a specific but still not fully mature barrier from the maternal blood circulation, and xenobiotics, including ENPs, have a greater chance to enter the fetal tissue and to affect its development, in this time window. ${ }^{[91]}$ Thus, ENPs might behave as embryotoxic agents in relation to their ability to cross the placenta, but also with dependence to the time of maternal exposure during pregnancy: ENPs unable to cross the placenta may nevertheless be embryotoxic if exposure occurs during the early stages of pregnancy. Of note, in most experimental studies showing embryotoxic effects, ENPs were administered within the first 10 days of pregnancy in 
rodents, ${ }^{[34,41,73,75,76,78,80-82]}$ a period roughly corresponding to the first trimester in humans.

Brain and testis are among the organs more frequently affected after in utero exposure. ${ }^{73,75,77,79,82,86]}$ clearly indicating the relevance of the incomplete development of internal biological barriers. Thus the combination of ENP translocation to the embryo, facilitated by the incomplete development of the placenta, and consequent brain and testis damage, favoured by the incomplete development of BBB and BTB, should be seriously considered in the case of early exposure to ENPs during pregnancy.

Second, structural alterations of the placenta itself reflex in embryotoxicity, even in the absence of ENP translocation to the embryo. As already mentioned, this is strictly linked to the dependency of the embryo on the efficient function of the placenta for nourishment and gas exchange. We and others have provided experimental data suggesting that this situation may occur in some cases after ENP exposure. ${ }^{[34,41]}$

Third, embryotoxicity may occur after lung exposure, ${ }^{[41,78,80-82]}$ the most common route of exposure in occupational setting. Furthermore, damage was observed at concentrations comparable to those present in work environment. ${ }^{[81]}$ Therefore, the possibility of embryotoxic effects of some ENPs at the expected exposure levels in humans may be considered substantial.

Finally, to date only one study has considered the possible adverse effects of ENP exposure through the oral route in pregnancy. ${ }^{[88]}$ Considering that in adults the effect on BBB and BTB after gastrointestinal exposure are in general more marked than after lung exposure, studies on possible embryotoxicity after oral exposure are needed.

\section{Do ENPs Impact on Injured Internal Barriers?}

Are studies available to address the impact of NPs with injured or compromised internal barriers? The few available data to date regard exclusively the BBB. Hence, some studies suggest that ENPs unable to cross $\mathrm{BBB}$, may nevertheless make the barrier more susceptible to the injury of other agents. Sharma et al. have shown that daily intraperitoneal injection $(30000 \mu \mathrm{g} / \mathrm{kg}$ ) of 50-60 nm Ag and $\mathrm{Cu}$ NPs for one week did not cause significant brain translocation or tissue damage. However, the subsequent exposure to heat stress caused greater BBB disruption and brain damage in animals previously exposed to these ENPs than in non exposed animals. ${ }^{[92]}$ The same authors showed also that the same ENPs injected intraperitoneally are able to cross the BBB and to cause brain damage in diabetic rats. ${ }^{[3]}$ Shin et al. ${ }^{[94]}$ have recently shown that $\mathrm{TiO}_{2}$ NPs do not induce brain inflammation when administered intraperitoneally to C57/BL6 mice; however, the NPs caused a significant increase of pro-inflammatory cytokines and of reactive oxygen species in animals previously exposed to the inflammogenic agent lipopolysaccharide (LPS).
The hypothesis that chronic conditions increase the rate of BBB crossing by NPs is supported by another study, showing that intravenously injected gold NPs do not cross BBB of normal rats, but they do in carcinoma-bearing animals. ${ }^{[95]}$ The growing number of people with chronic conditions suggests the need of further research on the possible increase of the CNS injuring potential in these vulnerable populations. On the other hand, it may also be of interest to reflect on the increasing number of in vitro studies demonstrating the ability of various types of NPs to either promote the nucleation of protein fibrillation ${ }^{[96]}$ or to inhibit fibrillation of proteins associated with neurodegenerative diseases. ${ }^{[97-99]}$ These studies add an interesting twist to the bio-corona concept ${ }^{[79]}$ and may imply that NPs that cross the BBB could have a therapeutic role in the prevention or treatment of neurodegenerative diseases such as Alzheimer's disease. However, the path from intriguing experimental observations to patients may not be straightforward in this particular instance given that the NPs in question could exert many other effects en route to the brain.

\section{Summary and Outlook}

Engineered nanoparticles (ENPs) must negotiate primary anatomical barriers such as the lung epithelium as well as internal barriers including the blood-brain barrier (BBB), the blood-testis barrier (BTB) and placental barrier in order to gain access to the inner sanctum of the brain, male reproductive organs, and fetus, respectively. Thus, in order to understand the potential hazard of ENPs towards these critical organs/offspring, one must understand the nature of biological barriers and how ENPs may cross these barriers, or interact with cellular components of the barriers leading to detrimental effects. It is also critically important to determine the physico-chemical properties of ENPs that impact on the interaction with biological barriers; in addition to the small size, other properties such as shape, surface charge, and so on also come into play. Importantly, each of these ENP properties will also likely influence the adsorption of biomolecules onto the surface of ENPs, and the bio-corona so formed may influence the distribution and toxicity potential of ENPs. Understanding the dynamic nature of the corona formation remains a key challenge in the field of nanosafety research, with obvious implications for nanomedicine, especially for targeted drug delivery. ${ }^{[17]}$ To this end, in vitro studies may serve as a starting point, but more complex, organotypic ex vivo models, along with in vivo studies are needed to fully appreciate the role of bio-corona formation.

It deserves to be pointed out that although the propensity of nanoparticles to cross biological barriers may give rise to unexpected, adverse effects on human health, this could also be exploited for therapeutic gain. A case in point, Kannan et al. ${ }^{[100]}$ recently reported on a potential treatment that alleviates the symptoms of cerebral palsy (CP) in newborn rabbits. The antioxidant, $\mathrm{N}$-acetyl-L-cysteine (NAC) was coupled to polyamidoamine dendrimers, which crossed the BBB and specifically localized in activated microglia and astrocytes in the brain 
of CP-induced rabbits. Needless to say, the long-term safety of dendrimers in humans needs to be addressed, but the study points to an interesting opportunity for targeted drug delivery in the neonatal period. On this note, it is important to realize that biological barriers may, indeed, present differences in the neonatal period. ${ }^{[101]}$ Further studies are needed that reflect different stages of maturity of biological barriers and also in vulnerable populations, and not only in healthy, adult individuals.

In the present review, we have discussed evidence indicating that ENPs may both cross and damage organs protected by internal barriers, possibly at doses and exposure routes expected in occupational and consumer setting. The in vivo studies provide important data on some ENPs showing a relatively high damaging potential, but information on a more extensive panel of consumer-relevant and worker-relevant ENPs is clearly needed. The process of barrier crossing follows probably different dynamics in different barriers, and appropriate long-term evaluations are also needed in order to understand the real hazard posed by exposure to a given ENP. In the particular case of the placenta barrier, different stages of its development may be associated with quite different outcomes after interaction with ENPs: once again appropriately designed studies are mandatory.

The data suggest that substantial damage to organs protected by internal barriers may arise in indirect ways, even in the absence of crossing. This possibility should be addressed using both in vitro and ex vivo models; relying on the equation no crossing=no damage may lead one to conclude that some ENPs are safe when they are actually dangerous. Of particular relevance, recent studies have disclosed that NPs may cause DNA damage to cells cultured below a barrier without actually crossing the barrier. ${ }^{[6]}$ Such indirect damage was seen across trophoblast barriers in vitro and studies using ex vivo explants of human placenta further substantiated the principle of indirect toxicity. Despite the caveats of using in vitro/ex vivo model systems, these results warrant consideration.

In the last decades we have been faced with a true epidemic of neurodegenerative diseases, ${ }^{[102]}$ a decline in male fertility, ${ }^{[103,104]}$ and an increasing age of child-bearing (and the associated increased chances of miscarriages and malformations). ENPs have been incriminated in all these conditions. ${ }^{[33,68]}$ Assessment of their safety in these contexts may thus have enormous clinical and social implications.

\section{Acknowledgements}

The authors are supported, in part, by the European Commission (FP7-MARINA; grant agreement 263215), the Italian Ministry of Health ("Finalizzato Salute" project RF-2009-1536665), the Swedish Research Council for Environment, Agricultural Sciences and Spatial Planning (FORMAS), and the Swedish Cancer and Allergy Foundation.
[1] G. J. Mahler, M. B. Esch, E. Tako, T. L. Southard, S. D. Archer, R. P. Glahn, M. L. Shuler, Nat. Nanotechnol. 2012, 7, 264.

[2] F. M. Kievit, M. Zhang, Adv. Mater. 2011, 23, H217.

[3] T. Xia, N. Li, A. E. Nel, Annu. Rev. Public Health 2009, 30, 137.

[4] A. A. Shvedova, A. Pietroiusti, B. Fadeel, V. E. Kagan, Toxicol. Appl. Pharmacol. 2012, 261, 121.

[5] E. Brun, M. Carrière, A. Mabondzo, Biomaterials 2012, 33, 886.

[6] A. Sood, S. Salih, D. Roh, L. Lacharme-Lora, M. Parry, B. Hardiman, R. Keehan, R. Grummer, E. Winterhager, P. J. Gokhale, P. W. Andrews, C. Abbott, K. Forbes, M. Westwood, J. D. Aplin, E. Ingham, I. Papageorgiou, M. Berry, J. Liu, A. D. Dick, R. J. Garland, N. Williams, R. Singh, A. K. Simon, M. Lewis, Nat. Nanotechnol. 2011, 6, 824.

[7] A. E. Nel, L. Mädler, D. Velegol, T. Xia, E. M. Hoek, P. Somasundaran, F. Klaessig, V. Castranova, M. Thompson, Nat. Mater. 2009, 8, 543.

[8] H. Zhang, K. E. Burnum, M. L. Luna, B. O. Petritis, J.-S. Kim, W.-J. Qian, R. J. Moore, A. Heredia-Langner, B.-J. M. Webb-Robertson, B. D. Thrall, D. G. Camp, R. D. Smith, J. G. Pounds, T. Liu, Proteomics 2011, 11, 4569.

[9] E. Casals, T. Pfaller, A. Duschl, G. J. Oostingh, V. F. Puntes, Small 2011, 7, 3479.

[10] M. Gasser, B. Rothen-Rutishauser, H. F. Krug, P. Gehr, M. Nelle, B. Yan, P. Wick, J. Nanobiotechnol. 2010, 8, 31.

[11] C. Schleh, B. Rothen-Rutishauser, W. G. Kreyling, Eur. J. Pharm. Biopharm. 2011, 77, 350e2.

[12] M. Semmler-Behnke, W. G. Kreyling, J. Lipka, S. Fertsch, A. Wenk, S. Takenaka, G. Schmid, W. Brandau, Small 2008, 4, 2108.

[13] A. A. Kapralov, W. H. Feng, A. A. Amoscato, N. Yanamala, K. Balasubramanian, D. E. Winnica, E. R. Kisin, G. P. Kotchey, P. Gou, L. J. Sparvero, P. Ray, R. K. Mallampalli, J. Klein-Seetharaman, B. Fadeel, A. Star, A. A. Shvedova, V. E. Kagan, ACS Nano 2012, 6, 4147.

[14] S. T. Stern, S. E. McNeil, Toxicol. Sci. 2008, 101, 4.

[15] D. B. Warheit, Anal. Bioanal. Chem. 2010, 398, 607.

[16] B. Marie-Alexandrine, B. Stéphanie, C. Yves, Wiley Interdiscip. Rev. Nanomed. Nanobiotechnol. 2011, DOI: 10.1002/ wnan.146.

[17] E. Mahon, A. Salvati, F. Baldelli Bombelli, I. Lynch, K. A. Dawson, J. Control. Release 2012, 16, 164.

[18] H. Jin, D. A. Heller, R. Sharma, M. S. Strano, ACS Nano 2009, 3, 149.

[19] X. Jiang, C. Röcker, M. Hafner, S. Brandholt, R. M. Dörlich, G. U. Nienhaus, ACS Nano 2010, 4, 6787.

[20] D. Simberg, W.-M. Zhang, S. Merkulov, K. McCrae, J.-H. Park, M. J. Sailor, E. Ruoslahti, J. Control. Release 2009, 140, 301.

[21] M. Zhu, G. Nie, H. Meng, T. Xia, A. Nel, Y. Zhao, Acc. Chem. Res. 2012, DOI: $10.1021 /$ ar300031y.

[22] W. G. Kreyling, M. Semmler-Behnke, J. Seitz, W. Scymczak, A. Wenk, P. Mayer, S. Takenaka, G. Oberdörster, Inhal. Toxicol. 2009, 21 Suppl 1, 55.

[23] C. Schleh, M. Semmler-Behnke, J. Lipka, A. Wenk, S. Hirn, M. Schäffler, G. Schmid, U. Simon, W. G. Kreyling, Nanotoxicology 2012, 6, 36.

[24] H. S. Choi, Y. Ashitate, J. H. Lee, S. H. Kim, A. Matsui, N. Insin, M. G. Bawendi, M. Semmler-Behnke, J. V. Frangioni, A. Tsuda, Nat. Biotechnol. 2010, 28, 1300.

[25] M. Geiser, B. Rothen-Rutishauser, N. Kapp, S. Schürch, W. Kreyling, H. Schulz, M. Semmler-Behnke, V. Im Hof, J. Heyder, P. Gehr, Environ. Health Perspect. 2005, 113, 1555.

[26] S. Bhaskar, F. Tian, T. Stoeger, W. Kreyling, J. M. de la Fuente, V. Grazú, P. Borm, G. Estrada, V. Ntziachristos, D. Razansky, Part. Fibre Toxicol. 2010, 7, 3.

[27] T. Buerki-Thurnherr, U. von Mandach, P. Wick, Swiss Med. Wkly. 2012, 142, w13559.

[28] F. Zhao, Y. Zhao, Y. Liu, X. Chang, C. Chen, Y. Zhao, Small 2011, $7,1322$. 
[29] M. W. Brightman, T. S. Reese, J. Cell. Biol. 1969, 40, 648.

[30] A. Tsuji, NeuroRX 2005, 2, 54.

[31] W. K. Boyes, R. Chen, C. Chen, R. A. Yokel, Neurotoxicology 2012, 33, 902.

[32] L. Su, D. D. Mruk, C. Y. Cheng, J. Endocrinol. 2011, 208, 207.

[33] Z. Lan, W.-X. Yang, Nanomedicine 2012, 7, 579

[34] A. Pietroiusti, M. Massimiani, I. Fenoglio, M. Colonna, F. Valentini, G. Palleschi, A. Camaioni, A. Magrini, G. Siracusa, A. Bergamaschi, A. Sgambato, L. Campagnolo, ACS Nano 2011, 5, 4624.

[35] M. A. Jepson, in Adverse Effects of Engineered Nanomaterials: Exposure, Toxicology, and Impact on Human Health (Eds: B. Fadeel, A. Pietroiusti, A. Shvedova) Elsevier, New York, US 2012, pp. 209-224.

[36] M. Geiser, W. G. Kreyling, Part. Fibre Toxicol. 2010, 7, 2.

[37] W. G. Kreyling, M. Semmler-Behnke, S. Takenaka, W. Möller, Acc. Chem. Res. 2012, doi: 10.1021/ar300043r.

[38] Z. Yang, Y. Zhang, Y. Yang, L. Sun, D. Han, H. Li, C. Wang, Nanomedicine: NBM 2010, 6, 427.

[39] E. J. Park, E. Bae, J. Yi, Y. Kim, K. Choi, S. H. Lee, J. Yoon, B. C. Lee, K. Park, Environ. Toxicol. Pharmacol. 2010, 30, 162.

[40] Y. S. Kim, M. Y. Song, J. D. Park, K. S. Song, H. R. Ryu, Y. H Chung, H. K Chang, J. H. Lee, K. H. Oh, B. J. Kelman, I. K. Hwang, I. J. Yu, Part. Fibre Toxicol. 2010, 7, 20.

[41] J. L. Blum, J. Q. Xiong, C. Hoffman, J. T. Zelikoff, Toxicol. Sci. 2012, 126, 478

[42] V. Sharma, P. Singh, A. K. Pandey, A. Dhawan, Mutat. Res. 2012, $745,84$.

[43] T. Xia, M. Kovochich, M. Liong, L. Mädler, B. Gilbert, H. Shi, J. I. Yeh, J. I. Zink, A. E. Nel, ACS Nano 2008, 2, 2121.

[44] J. Shi, H. L. Karlsson, K. Johansson, V. Gogvadze, L. Xiao, J. Li, T. Burks, A. Garcia-Bennett, A. Uheida, M. Muhammed, S. Mathur, R. Morgenstern, V. E. Kagan, B. Fadeel, ACS Nano 2012, 6, 1925.

[45] B. van Ravenzwaay, R. Landsiedel, E. Fabian, S. Burkhardt, V. Strauss, L. Ma-Hock, Toxicol. Lett. 2009, 186, 152

[46] S. Hirn, M. Semmler-Behnke, C. Schleh, A. Wenk, J. Lipka, M. Schäffler, S. Takenaka, W. Möller, G. Schmid, U. Simon, W. G. Kreyling, Eur. J. Pharm. Biopharm. 2011, 77, 407.

[47] A. Elder, R. Gelein, V. Silva, T. Feikert, L. Opanashuk, J. Carter, R. Potter, A. Maynard, Y. Ito, J. Finkelstein, G. Oberdörster, Environ. Health Perspect. 2006, 114, 1172.

[48] L. Zhang, R. Bai, B. Li, C. Ge, J. Du, Y. Liu, L. Le Guyarder, Y. Zhao, Y. Wu, S. He, Y. Ma, C. Chen, Toxicol. Lett. 2011, 207, 73.

[49] J. Wang, C. Chen, Y. Liu, F. Jiao, W. Li, F. Lao, Y. Li, B. Li, C. Ge, G. Zhou, Y. Gao, Y. Zhao, Z. Chai, Toxicol. Lett. 2008, 183, 72.

[50] L. Zhang, R. Bai, Y. Liu, L. Meng, B. Li, L. Wang, L. Le Guyarder, C. Chen, Nanotoxicology 2012, 6, 562.

[51] Y. Y. Kao, T. J. Cheng, D. M. Yang, C. T. Wang, Y. M. Chiung, P. S. Liu, J. Mol. Neurosci. 2012, 48, 464.

[52] G. Oberdörster, A. Elder, A. Rinderknecht, J. Nanosci. Nanotechnol. 2009, 9, 4996.

[53] X. He, H. Zhang, Y. Ma, W. Bai, Z. Zhang, K. Lu, Y. Ding, Y. Zhao, Z. Chai, Nanotechnology 2010, 21, 285103.

[54] M.-T. Zhu, W.-Y. Feng, J. Wang, B. Wang, M. Wang, H. Ouyang, Y. Zhao, Z. Chai, Toxicol. Sci. 2009, 107, 342.

[55] W. H. De Jong, W. I. Hagens, P. Krystek, M. C. Burger, A. J. A. M. Sips, R. E. Geertsma, Biomaterials 2008, 29, 1912.

[56] S. K. Balasubramanian, J. Jittiwat, J. Manikandan, C. N. Ong, L. E. Yu, W. Y. Ong, Biomaterials 2010, 31, 2034.

[57] R. A. Yokel, T. C. Au, R. MacPhail, S. S. Hardas, D. A. Butterfield, R. Sultana, M. Goodman, M. T. Tseng, M. Dan, H. Haghnazar, J. M. Unrine, U. M. Graham, P. Wu, E. A. Grulke, Toxicol. Sci. 2012, 127, 256

[58] L. P. Sychevaa, V. S. Zhurkova, V. V. Iurchenkoa, N. O. Daugel-Daugeb, M. A. Kovalenkoa, E. K. Krivtsova, A. D. Durnev, Mut. Res. 2011, 726, 8.
[59] A. A. Shemetov, I. Nabiev, A. Sukhanova, ACS Nano 2012, 6, 4585.

[60] S. Yoshida, K. Hiyoshi, T. Ichinose, H. Takano, S. Oshio, I. Sugawara, K. Takeda, T. Shibamoto, Int. J. Androl. 2008, 32, 337.

[61] R. Hu, X. Gong, Y. Duan, N. Li, Y. Che, Y. Cui, M. Zhou, C. Liu, H. Wang, F. Hong, Biomaterials 2010, 31, 8043.

[62] Y. O. Fan, Y. H. Zhang, X. P. Zhang, B. Liu, Wei Sheng Yan Jiu (J. Hygiene Res.) 2006, 35, 549.

[63] S. S. Hardas, D. A. Butterfield, R. Sultana, M. T. Tseng, M. Dan, R. L. Florence, J. M. Unrine, U. M. Graham, P. Wu, E. A. Grulke, R. A. Yokel, Toxicol. Sci. 2010, 116, 562.

[64] S. M. Hirst, A. Karakoti, S. Singh, W. Self, R. Tyler, S. Seal, C. M. Reilly, Environ. Toxicol. 2012, doi: 10.1002/tox.20704.

[65] Y. S. Chen, Y. C. Hung, L. W. Lin, I. Liau, M. Y. Hong, G. S. Huang, Nanotechnology 2010, 21, 485102.

[66] J. Tang, L. Xiong, S. Wang, J. Wang, L. Liu, J. Li, F. Yuan, T. Xi, J. Nanosci. Nanotechnol. 2009, 9, 4924.

[67] L. Chen, R. A. Yokel, B. Henning, M. Toborek, J. Neuroimmune Pharmacol. 2008, 3, 286.

[68] A. Pietroiusti, Nanoscale 2012, 4, 1231.

[69] Y. Morishita, Y. Yoshioka, H. Satoh, N. Nojiri, K. Nagano, Y. Abe, H. Kamada, S. Tsunoda, H. Nabeshi, T. Yoshikawa, Y. Tsutsumi, Biochem. Biophys. Res. Commun. 2012, 420, 297.

[70] Y. Bai, Y. Zhang, J. Zhang, Q. Mu, W. Zhang, E. R. Butch, S. E. Snyder, B. Yan, Nat. Nanotechnol. 2010, 5, 683.

[71] L. L. Guo, X. H. Liu, D. X. Qin, L. Gao, H. M. Zhang, J. Y. Liu, Y. G. Cui, Zhonghua Nan ke Xue (Natl. J. Andrology) 2009, 15, 517

[72] K. Yamashita, Y. Yoshioka, K. Higashisaka, K. Mimura, Y. Morishita, M. Nozaki, T. Yoshida, T. Ogura, H. Nabeshi, K. Nagano, Y. Abe, H. Kamada, Y. Monobe, T. Imazawa, H. Aoshima, K. Shishido, Y. Kawai, T. Mayumi, S. Tsunoda, N. Itoh, T. Yoshikawa, I. Yanagihara, S. Saito, Y. Tsutsumi, Nat. Nanotechnol. 2011, 6, 321.

[73] K. Takeda, K.-I. Suzuki, A. Ishihara, M. Kubo-Irie, R. Fujimoto, M. Tabata, S. Oshio, Y. Nihei, T. Ihara, M. Sugamata, J. Health Sci. 2009, 55, 95.

[74] L. Ma, J. Liu, N. Li, J. Wang, Y. Duan, J. Yan, H. Liu, H. Wang, F. Hong, Biomaterials 2010, 31, 99.

[75] Y. Takahashi, K. Mizuo, Y. Shinkai, S. Oshio, K. Takeda, J. Toxicol. Sci. 2010, 35, 749

[76] M. Shimizu, H. Tainaka, T. Oba, K. Mizuo, M. Umezawa, K. Takeda, Part. Fibre Toxicol. 2009, 6, 20.

[77] K. S. Hougaard, P. Jackson, K. A. Jensen, J. J. Sloth, K. Löschner E. H. Larsen, R. K. Birkedal, A. Vibenholt, A.-M. Z. Boisen, H. Wallin, U. Vogel, Part. Fibre Toxicol. 2010, 7, 16.

[78] P. Jackson, S. Halappanavar, K. S. Hougaard, A. Williams, A. M. Madsen, J. S. Lamson, O. Andersen, C. Yauk, H. Wallin, U. Vogel, Nanotoxicology 2011, doi:10.3109/17435390.2011. 633715.

[79] P. Jackson, U. Vogel, H. Wallin, K. S. Hougaard, Basic Clin. Pharmacol. Toxicol. 2011, 109, 434.

[80] P. Jackson, K. S. Hougaard, U. Vogel, D. Wuc, L. Casavantc, A. Williams, M. Wadec, C. Yauk, H. Wallin, S. Halappanavar, Mut. Res. 2012, 745, 73.

[81] P. Jackson, K. S. Hougaard, A. M. Z. Boisen, N. R. Jacobsen, K. A. Jensen, P. Moller, G. Brunborg, K. B. Gutzkow, O. Andersen, S. Loft, U. Vogel, H. Wallin, Nanotoxicology 2012, 6, 486.

[82] S. Yoshida, K. Hiyoshi, S. Oshio, H. Takano, K. Takeda, T. Ichinose, Fertil. Steril. 2010, 93, 1695.

[83] S. Takahashi, O. Matsuoka, J. Radiat. Res. 1981, 22, 242.

[84] M. Semmler-Behnke, S. Fertsch, O. Schmid, A. Wenk, W. G. Kreyling, Euro Nanoforum - Nanotechnology in Industrial Applications, http://www.euronanoforum2007.de/download/ Proceedings\%20ENF2007.pdf] 2007, 102. Accessed: May, 2012. 
[85] E. Sadauskas, H. Wallin, M. Stoltenberg, U. Vogel, P. Doering, A. Larsen, G. Danscher, Part. Fibre Toxicol. 2007, 4, 10.

[86] T. Tsuchiya, I. Oguri, Y. N. Yamakoshi, N. Miyata, FEBS Lett. 1996, 393, 139.

[87] S. C. J. Sumner, T. R. Fennell, R. W. Snyder, G. F. Taylor, A. H. Lewin, J. Appl. Toxicol. 2010, 30, 354.

[88] J. H. Lim, S. H. Kim, I. S. Shin, N. H. Park, C. Moon, S. S. Kang, S. H. Kim, S. C. Park, J. C. Kim, Birth Def. Res. B 2011, 92, 69.

[89] M. Chu, Q. Wu, H. Yang, R. Yuan, S. Hou, Y. Yang, Y. Zou, S. Xu, K. Xu, A. Ji, L. Sheng, Small 2010, 6, 670.

[90] L. Ye, K. T. Yong, L. Liu, I. Roy, R. Hu, J. Zhu, H. Cai, W. C. Law, J. Liu, K. Wang, J. Liu, Y. Liu, Y. Hu, X. Zhang, M. T. Swihart, P. N. Prasad Nat. Nanotechnol. 2012, doi: 10.1038/nnano.2012.74.

[91] G. Grazeliene, V. Zalgeviciene, V. Didziapetriene, J. Zukiene, A. Sukackaite, V. Legenis, R. Rotomskis, Medicina (Kaunas) 2006, 42, 142.

[92] H. S. Sharma, F. Muresanu, R. Patnaik, A. D. Stan, V. Vacaras, L. Perju-Dumbrav, B. Alexandru, A. Buzoianu, I. Opincariu, P. K. Menon, A. Sharma, J. Nanosci. Nanotechnol. 2011, 11, 5549.

[93] J. V. Lafuente, A. Sharma, R. Patnaik, D. F. Muresanu, H. S. Sharma, CNS Neurol. Disord. Drug Targets 2012, 11, 26.

[94] J. A. Shin, E. J. Lee, S. M. Seo, H. S. Kim, J. L. Kang, E. M. Park, Neuroscience 2010, 165, 445.

[95] L. S. Rieznichenko, S. M. Dybkova, T. G. Gruzina, Z. R. Ulberg, I. N. Todor, N. Y. Lukyanova, S. I. Shpyleva, V. F. Chekhun, Exp. Oncol. 2012, 34, 25.

[96] S. Linse, C. Cabaleiro-Lago, W.-F. Xue, I. Lynch, S. Lindman, E. Thulin, S. E. Radford, K. A. Dawson, Proc. Natl. Acad. Sci. USA 2007, 104, 8691
[97] C. Cabaleiro-Lago, F. Quinlan-Pluck, I. Lynch, S. Lindman, A. M. Minogue, E. Thulin, D. M. Walsh, K. A. Dawson, S. Linse, J. Am. Chem. Soc. 2008, 130, 15437.

[98] C. Cabaleiro-Lago, I. Lynch, K. A. Dawson, S. Linse, Langmuir 2010, 26, 3453.

[99] S. I. Yoo, M. Yang, J. R. Brender, V. Subramanian, K. Sun, N. E. Joo, S. H. Jeong, A. Ramamoorthy, N. A. Kotov, Angew Chem. Int. Ed. Engl. 2011, 50, 5110.

[100] S. Kannan, H. Dai, R. S. Navath, B. Balakrishnan, A. Jyoti, J. Janisse, R. Romero, R. M. Kannan, Sci. Transl. Med. 2012, 4, 130.

[101] M. Semmler-Behnke, W. G. Kreyling, H. Schulz, S. Takenaka, J. P. Butler, F. S. Henry, A. Tsuda, Proc. Natl. Acad. Sci. USA 2012, 109, 5092.

[102] L. E. Hebert, L. A. Beckett, P. A. Scherr, D. A. Evans, Alzheimer Dis. Assoc. Disord. 2001, 15, 169.

[103] J. Auger, J. M. Kunstmann, F. Czyglik, P. Jouannet, N. Engl. J. Med. 1995, 332, 281.

[104] S. Farrow, BMJ 1994, 309, 1.

[105] J. T. Kwon, S. K. Hwang, H. Jin, D. S. Kim, A. Minai-Tehrani, H. J. Yoon, M. Choi, T. J. Yoon, D. Y. Han, Y. W. Kang, B. I. Yoon, J. K. Lee, M. H. Cho, J. Occup. Health 2008, 50, 1.

[106] B. C. Lin, Z. G. Xi, Y. G. Zhang J. Environ. Health 2007, 24, 574.

[107] J. Wang, G. Zhou, C. Chen, H. Yu, T. Wang, Y. Ma, G. Jia, Y. Gao, B. Li, J. Sun, Y. Li, F. Jiao, Y. Zhao, Z. Chai, Toxicol. Lett. 2007, $168,176$.

Received: June 27, 2012

Revised: September 13, 2012

Published online: 